\title{
Understanding the impact of 5-HTTLPR, antidepressants, and acute tryptophan depletion on brain activation during facial emotion processing: A review of the imaging literature
}

\author{
Kyeon Raab ${ }^{\mathrm{a}, \mathrm{b}, *}$, Peter Kirsch ${ }^{\mathrm{a}}$, Daniela Mier $^{\mathrm{a}}$ \\ a Department of Clinical Psychology, Central Institute of Mental Health, Medical Faculty Mannheim, University of Heidelberg, Square J5, 68159 Mannheim, \\ Germany \\ ${ }^{\mathrm{b}}$ Department of Psychiatry and Psychotherapy, Philipps-University Marburg, Rudolf-Bultmann-Strasse 8, 35039 Marburg, Germany
}

\section{Keywords:}

5-HTTLPR

Acute tryptophan depletion

Amygdala

Anterior cingulate cortex

Candidate gene

Corticolimbic

Emotion

Emotion recognition

Face processing

Imaging genetics

Medial prefrontal cortex

Orbitofrontal cortex

Serotonin

Serotonin receptor

Serotonin transporter

Social cognition

SSRI

\section{Contents}

\section{A B S T R A C T}

Detecting and evaluating emotional information from facial expressions as a basis for behavioural adaption belong to the core social-cognitive abilities of mankind. Dysfunctions in emotional face processing are observed in several major psychiatric disorders like depression and schizophrenia. In search for psychiatric disease biomarkers using the imaging genetics approach, serotonergic gene polymorphisms have been associated with altered brain circuit activation during emotional face processing. Especially the 5HTTLPR gene polymorphism has been extensively investigated in association with emotion regulation processes. In this article, imaging genetics literature on emotional face processing, reporting genetic effects of 5-HTTLPR in healthy volunteers is reviewed. Additionally, these results are regarded in relation to pharmacologic challenge (antidepressants, acute tryptophan depletion) imaging studies and discussed in light of recent neurobiological evidence with a focus on serotonin (5- $\left.\mathrm{HT}_{1 \mathrm{~A}}, 5-\mathrm{HT}_{2 \mathrm{C}}, 5-\mathrm{HT}_{2 \mathrm{~A}}\right)$ receptor findings.

1. Introduction

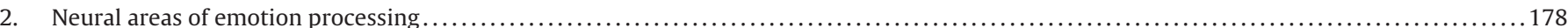

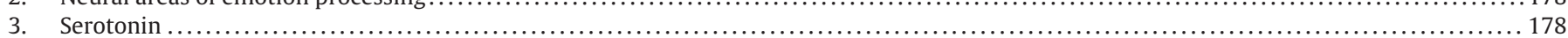

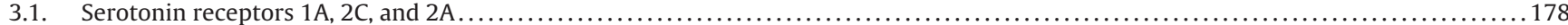

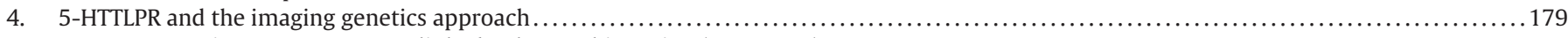

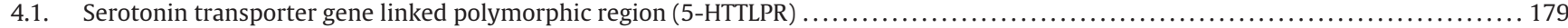

\footnotetext{
* Corresponding author at: Department of Psychiatry and Psychotherapy, Philipps-University Marburg, Rudolf-Bultmann-Strasse 8, 35039 Marburg, Germany. E-mail addresses: Kyeon.Raab@med.uni-marburg.de, Kyeon.Raab@gmail.com (K. Raab), Peter.Kirsch@zi-mannheim.de (P. Kirsch), Daniela.Mier@zi-mannheim.de (D. Mier).
} 


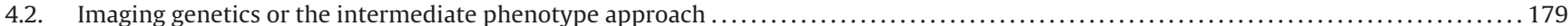

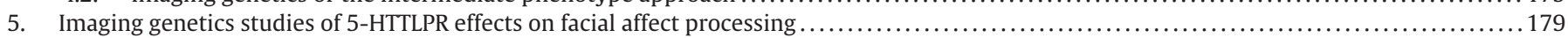

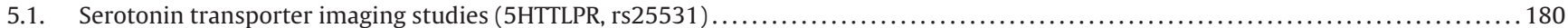

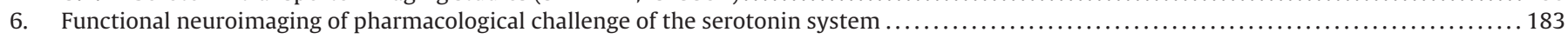

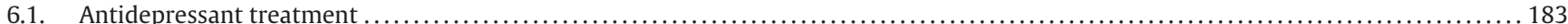

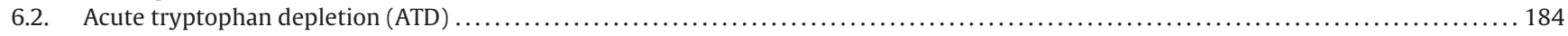

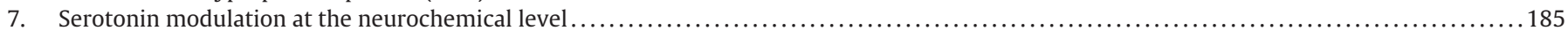

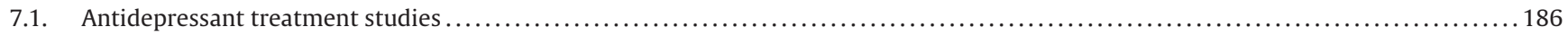

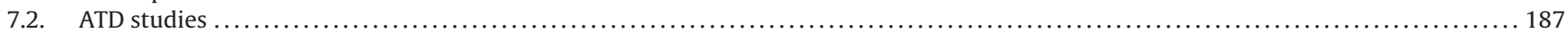

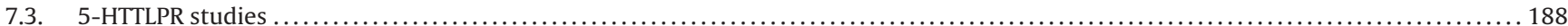

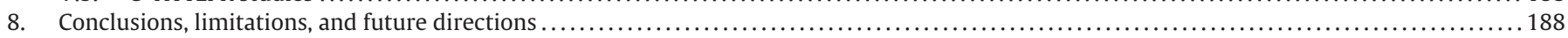

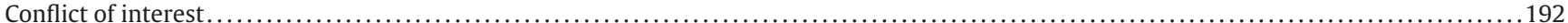

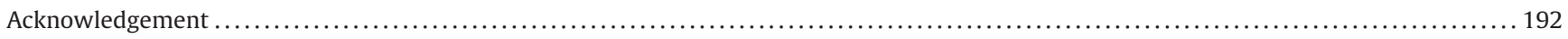

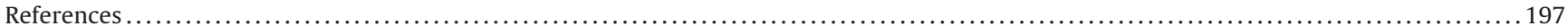

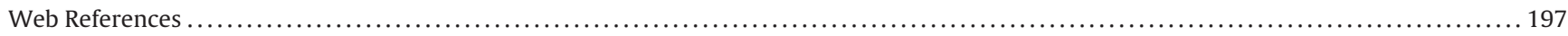

\section{Introduction}

In the last decades, genetic risk factors for mental illnesses have been brought more and more into focus of the clinical neurosciences. This development dates back to the second half of the 20th century when the investigation of the mind became increasingly integrated in the biological study of the brain (Kandel and Squire, 2000). Along with the awareness that even most complex psychological processes are results of brain function, came the insight that behaviour is driven by the interaction of neural brain circuits (Kandel, 1998). These neural interconnections are modulated by genes and their protein products (e.g., receptors, transporters, and metabolic enzymes) which have gained a significant role in the investigation of psychiatric diseases (Cloninger, 2002; Cowan et al., 2002; Hyman, 2000; Kandel, 1998), such as schizophrenia (Birnbaum and Weinberger, 2013; Giusti-Rodríguez and Sullivan, 2013; Harrison and Weinberger, 2005), autism (Meek et al., 2013; Persico and Napolioni, 2013), or affective disorders (Craddock and Sklar, 2013; Flint and Kendler, 2014; Seifuddin et al., 2013). In the course of analyzing the influence of genes on mental disorders, it has become well-established to investigate in healthy, as well as in clinical populations, the genetic impact on particular behavioural aspects or specific brain functions which have been observed to be deviant in mental illness, e.g., memory (Karlsgodt et al., 2011; Tan et al., 2009), attention (Barnes et al., 2011; Logue and Gould, 2014), or social cognition (Iarocci et al., 2007; Skuse and Gallagher, 2011).

"Social cognition" is a term first introduced into neuroscience by Leslie Brothers within her "social brain hypothesis", defined as the processing of all information relevant for "the accurate perception of the dispositions and intentions of other individuals" (Brothers, 1990 , p. 28). According to this definition, the relevant information encompasses "social signals" referring to "identity, direction of movement, category of posture, facial expression, quality of vocalization, and knowledge of which other individuals are present and what their mutual relations are" (Brothers, 1990, p. 28). Regarding this concept, the appropriate processing of emotional information appears essential for social communication.

Adolphs defines an emotion as "a concerted, generally adaptive, phasic change in multiple physiological systems in response to the value of a stimulus" (Adolphs, 2002a, p. 24). The facial configuration of an emotion can express emotional states which are observed to be universally recognizable (Ekman, 1992). Already in 1872, Darwin remarked that "the force of language is much aided by the expressive movements of the face and body" (Darwin, 1872/1965, p. 354). As face processing and emotion recognition are the foundation for higher-order functions like empathy or theory of mind (Brothers and Ring, 1992; Decety and Jackson, 2004; Mier et al., 2010b,c), its dysfunction might contribute to social cognition deficits in psychiatric illnesses (Bragado-Jimenez and Taylor, 2012; Cusi et al.,
2012; Frith and Corcoran, 1996; Hoertnagl and Hofer, 2014; Lee et al., 2004; Thoma et al., 2013). And indeed, the processing of such emotional faces is observed to be disturbed in major psychiatric diseases like schizophrenia (Kohler et al., 2010; Morris et al., 2009) and depression (Bourke et al., 2010; Demenescu et al., 2010; Leppänen, 2006).

The neurotransmitter serotonin plays a major role in emotion processing (Del-Ben et al., 2008; Evers et al., 2010; Harmer, 2008). The serotonergic influence on facial emotion processing has been widely studied using functional magnetic resonance imaging, fMRI. With the rise of the imaging genetics approach (Bigos and Weinberger, 2010; Meyer-Lindenberg, 2012; MeyerLindenberg and Weinberger, 2006) (see also Chapter 4.2), especially one gene polymorphism has gained attention in the search for effects of genes coding for proteins with an influence on the serotonin system, the serotonin transporter (5-HTT) gene linked polymorphic region, abbreviated with 5-HTTLPR (Heils et al., 1996; Lesch et al., 1996). Using fMRI, this gene polymorphism has been shown to have an impact on brain circuits activation associated with emotion processing, including limbic and frontal areas (Canli and Lesch, 2007; Hariri and Holmes, 2006; Meyer-Lindenberg and Weinberger, 2006). Besides genetics, another approach to investigate sertonergic effects on facial emotion processing is to have a look at the acute pharmacological modulation of serotonin levels. Especially two types of pharmacological challenge studies have been widely accepted to investigate serotonergic effects: acute tryptophan depletion and the use of antidepressants. The amino acid tryptophan is a precursor protein of serotonin (Wurtman et al., 1980). An acute tryptophan depletion (ATD) is thought to decrease the serotonin metabolism in the central nervous system (Reilly et al., 1997). In a review by Evers and colleagues on neuroimaging studies investigating the processing of facial emotions using ATD, the overall finding was an increase of amygdala activation associated with ATD (Evers et al., 2010). Concerning serotonergic antidepressant effects, especially serotonin-reuptake inhibitors (SSRI), such as citalopram and escitalopram, have been shown to modulate activation in limbic brain regions during the processing of facial emotions (Harmer, 2008). A comparable effect was found for other antidepressants modulating central nervous serotonin, e.g., the extract of the plant Sceletium tortuosum (Zembrin) and duloxetine (Terburg et al., 2013; Van Marle et al., 2011).

Imaging genetics studies offer an instrument to delineate neural functional architecture associated with genetically driven alterations of a neuropsychiatric phenotype. Linking these investigations to pharmacologic challenge studies might validate suggested neurobiological mechanistic underpinnings of these observed alterations. Combining these different neuroimaging approaches might furthermore lead to neurobiological models bearing a chance for a deeper understanding of underlying neuronal 
mechanisms, promoting hope for a refined drug development, and thus a personalized psychopharmacological treatment. With this in mind, the focus of this review is on fMRI studies using emotional faces tasks, investigating the aforementioned serotonergic modulatory effects on brain activation: 5-HTTLPR-driven genetic variation and the pharmacological influence of ATD and antidepressants. Furthermore, these findings are evaluated in the light of recent neuroscientific literature.

In the following chapter an overview of the cerebral areas relevant for facial emotion processing will be given.

\section{Neural areas of emotion processing}

The neuroanatomical basis for the processing of emotions expressed in faces has been investigated extensively, leading to the detection of a neural network consisting of several limbic and frontal brain areas (Adolphs, 2002a,b, 2001; Haxby et al., 2000, 1999).

Out of the limbic structures, the amygdala is the subcortical brain area that has been dominantly associated with fear processing and threat detection (Adolphs, 2001; Adolphs et al., 1995). In addition, identifying the emotional significance of a stimulus and producing emotional states from it have been hypothesized as critical amygdala functions (Calder et al., 2001). On the anatomical level, the amygdala is interconnected to orbitofrontal cortex (OFC), anterior cingulate cortex (ACC) and medial prefrontal cortex (MPFC) (Barbas and De Olmos, 1990; Ghashghaei and Barbas, 2002; Paus, 2001). The OFC, like the amygdala, is part of the limbic system and has functionally been associated with stimulus-reinforcement association learning (Kringelbach and Rolls, 2004), as well as with the evaluation of emotional stimuli (Rolls and Grabenhorst, 2008; Rule et al., 2002; Shimamura, 2000), and the linking of sensory representations with social judgments on the basis of motivational value (Adolphs, 2003). The ACC is thought to be functionally crucial for cognition, e.g., error detection and conflict-monitoring (Carter et al., 1998; Paus, 2001), as well as social cognition, e.g., theory of mind (Frith and Frith, 2006, 1999; Gallagher and Frith, 2003). The MPFC is likewise assumed to be of importance for social cognitive functioning, e.g., theory of mind (Frith and Frith, 2006, 2003; Gallagher and Frith, 2003), and furthermore to represent the cerebral integration of self-referential information (Gusnard et al., 2001). Growing evidence suggests these four areas, amygdala, OFC, ACC, and MPFC, to be part of a neural circuit important for emotion processing. Moreover, especially the regulatory interactions between amygdala and the frontal areas are suggested to play a key role in affect processing. The contribution of these brain regions to social cognition (Adolphs, 2001; Frith and Frith, 2006, 2003; Gallagher and Frith, 2003), especially for the processing of emotional facial expressions hints at the possible relevance of this circuit.

Supported by animal and human data, an interregulatory relationship between amygdala and MPFC is widely accepted, i.e., MPFC function counterbalancing amygdala activation (Heinz et al., 2005; Maren and Quirk, 2004; Meyer-Lindenberg et al., 2006, 2005; Pezawas et al., 2005; Quirk et al., 2006; Rauch et al., 2006; Stefanacci and Amaral, 2002; Stein et al., 2007). Since published data show at most sparse direct anatomical connections between MPFC and amygdala (Amaral and Price, 1984; Carmichael and Price, 1995; Ghashghaei and Barbas, 2002), a mediating function of the ACC between these two regions has been hypothesized (Buckholtz and Meyer-Lindenberg, 2008; Meyer-Lindenberg et al., 2006; Pezawas et al., 2005; Stein et al., 2007). Furthermore, investigations by Meyer-Lindenberg and colleagues indicate that, in case of a compromised ACC functioning, a compensatory control function is provided by the OFC (Meyer-Lindenberg et al., 2006, 2005; Stein et al., 2007), indicating a complex interactive modulatory loop between these four areas.

In the following, a review of the central nervous serotonergic system will be presented. Within this chapter, the relevance of serotonin for the brain circuit introduced above will be outlined. Then, evidence of genetically driven serotonergic modulation of this circuit will be reviewed.

\section{Serotonin}

The serotonin system is a phylogenetically ancient neurotransmitter system and is suggested to have already been established in the nervous system of invertebrate ancestors (Hay-Schmidt, 2000). Over the last decades, neuronal serotonin signaling has been revealed to be substantially involved in cognitive and emotional functioning of the brain (Cools et al., 2008; Olivier, 2015) and has specifically been related to the processing of emotional faces (DelBen et al., 2008).

Serotonergic neurons primarily project from midline structures of the brain stem, the dorsal and median raphe nuclei, to the cerebral cortex, including the MPFC and the cingulate cortex, as well as to limbic structures such as the amygdala (Andrade and Haj-Dahmane, 2013; Jacobs and Azmitia, 1992; Kiyasova and Gaspar, 2011; Moore et al., 1978; Raghanti et al., 2008). Effects of serotonergic neurotransmission are mediated by specific receptors on serotonin target cells. Presently, the serotonin (5hydroxytryptamine, 5-HT) receptors are divided into seven classes (5- $\left.\mathrm{HT}_{1-7}\right)$, which are again subdivided into several subclasses (e.g., $5-\mathrm{HT}_{1 \mathrm{~A}}, 5-\mathrm{HT}_{1 \mathrm{~B}}$ etc.) to a total of 14 different 5 - $\mathrm{HT}$ receptors (Barnes and Sharp, 1999; Hoyer et al., 2002, 1994). All of the 5-HT receptors are localized postsynaptically on serotonin target cells, with the exception of the $5-\mathrm{HT}_{1 \mathrm{~A}}, 5-\mathrm{HT}_{1 \mathrm{~B}}$, and $5-\mathrm{HT}_{1 \mathrm{D}}$ receptors, which additionally serve as presynaptic autoreceptors on serotonergic neurons regulating the serotonin release (Barnes and Sharp, 1999; Hoyer et al., 2002; Roberts et al., 2001). Other subtypes (e.g., 5-HT 1 , $5-\mathrm{HT}_{5 \mathrm{~A}}$, and $5-\mathrm{HT}_{7}$ ) are regarded as potential candidates for additional autoreceptors (Roberts et al., 2001). Raphe nuclei serotonin release is thought to be regulated in a complex manner, but particularly the MPFC has been shown to modulate raphe serotonin release (Coplan et al., 2014). Since serotonin cannot cross the blood-brain barrier (Cansev and Wurtman, 2007; Pardridge, 1979), its predecessor tryptophan is essential for the serotonin synthesis which is regulated by tryptophan hydroxylase (TPH) activity (Matthes et al., 2010; Nakamura and Hasegawa, 2007). The serotonin-reuptake from the synaptic cleft is regulated by the serotonin transporter (5-HTT) which thereby regulates the 5-HT receptor stimulation (Munafò et al., 2008).5-HTT is one of the best studied serotonin sites and its gene is regarded as a key influence on facial emotion processing and affective disease development (Canli and Lesch, 2007; Hariri and Holmes, 2006; Hariri et al., 2005).

\subsection{Serotonin receptors $1 A, 2 C$, and $2 A$}

Especially three serotonin receptor subtypes have been related to emotion processing and corticolimbic signaling: the serotonin receptors $1 \mathrm{~A}, 2 \mathrm{C}$, and $2 \mathrm{~A}$.

The serotonin receptor $1 \mathrm{~A}\left(5-\mathrm{HT}_{1 \mathrm{~A}}\right)$ has been associated with emotion processing (Altieri et al., 2013) and with psychiatric disorders presenting with alterations in emotion regulation like depression and anxiety disorder (Akimova et al., 2009; Savitz et al., 2009). The $5-\mathrm{HT}_{1 \mathrm{~A}}$ receptor serves as an inhibitory somatodendritic autoreceptor and postsynaptic receptor (Barnes and Sharp, 1999; Riad et al., 2000; Sotelo et al., 1990; Verge et al., 1985). In raphe nuclei neurons the 5- $\mathrm{HT}_{1 \mathrm{~A}}$ receptor has mainly autoreceptor function, while in cortico-limbic areas the receptor usually lies 
postsynaptic to serotonergic nerve terminals (Celada et al., 2004, 2001). Furthermore, a 5- $\mathrm{HT}_{1 \mathrm{~A}}$ receptor-driven autoregulatory function between MPFC and dorsal raphe nuclei has been reported (Casanovas et al., 1999; Celada et al., 2001; Hajós et al., 1999, 1998; Jankowski and Sesack, 2004).

For a deeper understanding of 5- $\mathrm{HT}_{1 \mathrm{~A}}$ receptor effects on emotion processing, it is worth looking at its interaction with other serotonin receptors. In 5-HTT knockout mice, parallel to $5-\mathrm{HT}_{1 \mathrm{~A}}$ reduction (Holmes et al., 2003), an upregulation of 5- $\mathrm{HT}_{2 \mathrm{C}}$ receptors was observed (Li et al., 2003). The 5- $\mathrm{HT}_{2 \mathrm{C}}$ receptor is a postsynaptic receptor in various brain regions, e.g., in the amygdala (Drago and Serretti, 2009). Its activity is probably modulated by GABAergic and glutamatergic interneurons (Chen et al., 2003; Stein et al., 2000). It has been associated with several psychiatric illnesses associated with alterations in emotion processing like depression (Vimaleswaran et al., 2010) and bipolar disorder (Lerer et al., 2001), and has been linked to suicide (Videtic et al., 2009). Besides 5-HT and $5-\mathrm{HT}_{2 \mathrm{C}}$ receptors, one more 5 -HT receptor increasingly came into focus of emotion processing research, the $5-\mathrm{HT}_{2 \mathrm{~A}}$ receptor.

The $5-\mathrm{HT}_{2 \mathrm{~A}}$ receptor has raised attention especially in the treatment of schizophrenia with atypical neuroleptics, which show high affinity to it (Ebdrup et al., 2011; Richtand and McNamara, 2008). In the prefrontal cortex the $5-\mathrm{HT}_{2 \mathrm{~A}}$ receptor is expressed in pyramidal neurons and interneurons (Santana et al., 2004; Willins et al., 1997) and is functionally involved in the modulation of GABA and glutamate release (Abi-Saab et al., 1999; Aghajanian and Marek, 1999; De Almeida and Mengod, 2007; Jakab and Goldman-Rakic, 1998; Leysen, 2004; Miner et al., 2003). In terms of functional activity and cellular distribution, the $5-\mathrm{HT}_{2 \mathrm{~A}}$ resembles the $5-\mathrm{HT}_{2 \mathrm{C}}$ receptor (Aloyo et al., 2010; Leysen, 2004). In comparison to the $5-\mathrm{HT}_{1 \mathrm{~A}}$ receptor, the $5-\mathrm{HT}_{2 \mathrm{~A}}$ receptor is observed to exert opposite effects (Hernández et al., 2010; Klein et al., 2010; Yuen et al., 2008). On the animal level, Amargós-Bosch et al. (2004) reported that in prefrontal cortices of rodents $5-\mathrm{HT}_{1 \mathrm{~A}}$ and $5-\mathrm{HT}_{2 \mathrm{~A}}$ receptors are expressed highly co-localized ( $\sim 80 \%)$. While electrically stimulating raphe nuclei areas, they recorded $5-\mathrm{HT}_{1 \mathrm{~A}}$-mediated inhibitions and $5-\mathrm{HT}_{2 \mathrm{~A}}$-mediated excitations in medial prefrontal neurons. Using microdialysis, they could observe that the prefrontal $5-\mathrm{HT}_{2 \mathrm{~A}}$ agonist-mediated serotonin elevation was reduced by $5-\mathrm{HT}_{1 \mathrm{~A}}$ agonism. This indicates a counterbalancing regulatory relationship between these two receptor subtypes. Regarding emotion regulation, especially serotonergic projections from PFC to amygdala have been proposed to be $5-\mathrm{HT}_{2 \mathrm{~A}}$ receptor-mediated (Aznar and Klein, 2013).

\section{5-HTTLPR and the imaging genetics approach}

\subsection{Serotonin transporter gene linked polymorphic region (5-HTTLPR)}

The gene coding for 5-HTT, SLC6A4, is located on chromosome 17, more specifically at 17q11.1-17q12 (Ramamoorthy et al., 1993). In 1996, Lesch and colleagues found a functional polymorphism in the promotor region of this gene which became known as 5-HTT gene linked polymorphic region or 5-HTTLPR (Heils et al., 1996; Lesch et al., 1996). This polymorphism was characterized by two allele variants, a short (S) and a long (L) allele, differing in the number of a 20-23-base pair repeat unit (Heils et al., 1996; Lesch et al., 1996). Especially the $S$ allele has been associated with a decrease in 5-HTT mRNA and thus lesser 5-HTT expression and consequently higher synaptic serotonin levels (Lesch et al., 1996). More recently, the gene effect has been indicated to be of higher complexity, encompassing several different 5 -HT receptor regulations besides 5 -HTT variation (Hariri and Holmes, 2006). The discovery of an A-G single nucleotide substitution within the L allele (rs25531) led to a triallelic classification of 5-HTTLPR with $\mathrm{S}, \mathrm{L}_{\mathrm{G}}$, and $\mathrm{L}_{\mathrm{A}}$ allele $(\mathrm{Hu}$ et al., 2006; Nakamura et al., 2000; Wendland et al., 2006). In studies considering rs25531, the $\mathrm{L}_{\mathrm{G}}$ allele was grouped with $\mathrm{S}$ allele due to its equivalent function (Murphy et al., 2013). Specifically, the $S$ allele tends to be linked with an altered risk for depression (Uher and McGuffin, 2010). Furthermore, S allele carriers are prone to neuroticism or trait anxiety which in turn is a trait related to anxiety disorder and depression. Therefore, the $\mathrm{S}$ allele is regarded as increasing susceptibility for these illnesses (Canli and Lesch, 2007; Munafò et al., 2006; Schinka et al., 2004). (Regarding genetic susceptibility, scientists frequently use the terms "vulnerability genes" or "allelic risk". According to Belsky et al. (2009), this terminology is regarded as inappropriate, due to known gene-environment interactions. Since different genetic polymorphisms come along with different individual susceptibility to adverse or supportive environments, the authors consider the term "plasticity genes" as more appropriate. Especially for 5-HTTLPR, some studies showed that the $\mathrm{S}$ (as compared to $\mathrm{L}$ ) allele when co-ocurring with adverse life events promotes a depressive developement, whereas when cooccuring with supportive environments, reduces depression (Caspi et al., 2003; Taylor et al., 2006; Zammit and Owen, 2006). However, this concept is still under debate (e.g., Karg et al., 2011; Risch et al., 2009).

On the neural level, 5-HTTLPR variation has been particularly linked to altered amygdala activation in response to aversive stimuli (Munafò et al., 2008; Murphy et al., 2013). An overviev of studies reporting 5-HTTLPR effects on relevant brain activation during emotional face processing tasks will be given below.

\subsection{Imaging genetics or the intermediate phenotype approach}

Gottesman and Gold defined an "endophenotype" (or "intermediate phenotype") as a trait meeting the 5 criteria of (1) association with an illness in the population, (2) heritability, (3) primary stateindependence, (4) co-segregation with illness in families, and (5) occurrence in nonaffected family members in higher frequency than in the general population (Gottesman and Gould, 2003). The imaging genetics approach follows the rationale of identifying genetic effects of candidate genes at the level of neural systems and circuits level based on the intermediate phenotype concept (Bigos and Hariri, 2007; Hariri et al., 2006; Meyer-Lindenberg and Weinberger, 2006). The neurobiological correlates of emotion processing have been investigated as intermediate phenotypes being modulated by serotonin transporter gene variants (Canli and Lesch, 2007; Hariri and Holmes, 2006). Furthermore, 5-HTTLPR has been linked with anxiety (Domschke and Dannlowski, 2010; MeyerLindenberg and Weinberger, 2006) and seems to have an impact on affect-driven activation patterns between MPFC and amygdala (Bevilacqua and Goldman, 2011; Heinz et al., 2005).

Due to the involvement of the amygdala, OFC, ACC, and MPFC in both, emotion processing (Adolphs et al., 1999; Heinz et al., 2005; Paus, 2001; Rolls and Grabenhorst, 2008; Stein et al., 2007) and social cognition (Adolphs, 2001; Frith and Frith, 2006, 2003; Gallagher and Frith, 2003), a modulating influence of serotonin in the processing of facial expressions as an emotion-related and social-cognitive function seems likely. Coming in detail to neuroimaging investigations on 5-HTTLPR genotype effects regarding emotional face processing, an overview of relevant studies will be given in the following section.

\section{Imaging genetics studies of 5-HTTLPR effects on facial affect processing}

The PubMed database search for relevant imaging studies was conducted by using one of the terms "serotonin", "serotoner- 
gic", and "5-HTTLPR" in combination with one of the keywords "emotion recognition", "affect recognition", "emotion processing", "affect processing", "face processing", "facial affect", and "facial emotion". The imaging genetics studies included in this review were restricted to data on healthy volunteers with no family history of psychiatric disease to exclude abnormalities as a consequence of a psychiatric disorder, focusing on effects as possible susceptibility markers. Furthermore, we did not include studies not clearly investigating emotional face processing separately from cognitive brain functions like working memory, e.g., with a task using emotional stimuli (emoback-task, Jonassen et al., 2013), or studies using faces as distractors in a primarily cognitive testing, e.g., in the emotional alphabet task (Kilford et al., 2014). The final search for this review was conducted in January 2016. The search process revealed a total of 813 publications. Only 25 studies fulfilled the inclusion criteria for the purpose of the review. 22 reported brain activation differences associated with the 5-HTTLPR polymorphism (Battaglia et al., 2012; Bertolino et al., 2005; Canli et al., 2006, 2008; Dannlowski et al., 2010; Domschke et al., 2012; Fisher et al., 2015, 2014; Hariri et al., 2005, 2002; Lee and Ham, 2008; Lonsdorf et al., 2011; O'Nions et al., 2011; Pezawas et al., 2005; Surguladze et al., 2012, 2008; Thomason et al., 2010; Volman et al., 2013; Von dem Hagen et al., 2011; Walsh et al., 2012; Waring et al., 2014; Wiggins et al., 2014). Two of the 22 5-HTTLPR studies reported additionally TPH2 genotype related brain activation (Canli et al., 2008; Lee and Ham, 2008). Unlike Lee and Ham who reported effects related to the single genes (Lee and Ham, 2008), Canli and colleagues reported an additive gene-gene effect of TPH2 with 5-HTTLPR alleles (Canli et al., 2008). Of the 25 studies, only eleven groups focused on the SNP rs25531 in their analyses, a functional polymorphism suggested to modulate the transcriptional efficacy of 5-HTTLPR (Canli et al., 2006; Costafreda et al., 2013; Dannlowski et al., 2010, 2008; Domschke et al., 2012; Fisher et al., 2015, 2014; O’Nions et al., 2011; Surguladze et al., 2012; Thomason et al., 2010; Wiggins et al., 2014). Two groups decided to follow a biallelic approach due to group size issues (Canli et al., 2006; Thomason et al., 2010). The present review of these studies will be restricted to genotype-driven activity and connectivity related to the core areas of emotion processing that are also involved in face processing, namely amygdala, ACC, OFC, and MPFC.

\subsection{Serotonin transporter imaging studies (5HTTLPR, rs25531)}

Regarding the fMRI paradigms, six studies used a face matching task in which two identical faces out of a set of three faces with emotional or neutral expressions had to be identified (Hariri et al., 2000). The fMRI study by Hariri and colleagues from 2002 (Hariri et al., 2002) was the first publication reporting 5-HTTLPR-associated brain activation differences related to emotional processing. S allele carriers showed increased right amygdala response to fearful stimuli as compared to homozygous $\mathrm{L}$ allele subjects. This finding was replicated in three further studies (Bertolino et al., 2005; Domschke et al., 2012; Hariri et al., 2005). Two studies found no gene-driven activation differences (Bastiaansen et al., 2014; Pezawas et al., 2005). In 2005, Pezawas and colleagues published a study (Pezawas et al., 2005) reporting functional and structual MRI data. The authors found reduced functional connectivity between amygdala and perigenual ACC (pACC), particularly prominent in rostral subgenual ACC, in S allele carriers as compared to L allele homozygous subjects. The functional coupling between amygdala and ventromedial prefrontal cortex (BA 10) was slightly increased in S allele carriers which is discussed as evidence for dysregulated amygdalaACC circuitry. On a structural level, S allele carriers showed reduced grey matter density of pACC and right amygdala with stronger differences in comparison to L allele carriers in pACC.

Taken together, the studies using the face matching task indicated heightened amygdala activation and slightly increased functional coupling with MPFC, while functional connectivity between amygdala and ACC was reduced in association with the $S$ allele.

Another paradigm that was frequently used for investigating 5-HTTLPR effects on brain activation is an implicit emotion processing paradigm, too. In this paradigm, participants are asked to recognize the gender of faces with an emotional expression (Morris et al., 1996; Phillips et al., 1997). Using this paradigm, increased amygdala activation in $\mathrm{S}$ allele carriers was shown in four studies (Battaglia et al., 2012; Canli et al., 2008; Walsh et al., 2012; Wiggins et al., 2014). However, three studies could not replicate this finding (Costafreda et al., 2013; O'Nions et al., 2011; Surguladze et al., 2008), one study only reported genotype x environment interaction effects (Canli et al., 2006), and Fisher et al. (2015) even found an opposite effect for angry faces, but a congruent one for fearful faces. Most of these studies did not only focus on amygdala activation, but also on activation and connectivity in other regions important for face processing. O'Nions et al. (2011) found decreased subgenual ACC response to fearful relative to neutral faces in $\mathrm{L}_{\mathrm{A}}$ allele homozygous subjects and an increase of subgenual ACC activity in homozygous $\mathrm{S}$ allele carriers. Surguladze et al. (2008) reported increased functional connectivity of amygdala and fusiform gyrus in homozygous $\mathrm{S}$ allele carriers during prototypical fearful facial expressions as compared to heterozygous or homozygous L allele subjects. Canli et al. (2008) reported a significant positive correlation between right ACC activation, 5HTTLPR S allele and TPH2T allele for happy facial expressions. In a study investigating the effect of bright-light therapy, Fisher and colleagues found an increased intraprefrontal functional coupling in the medial PFC in the angry and fearful versus neutral faces contrast (Fisher et al., 2014). Regarding 5-HTTLPR alleles, the authors reported a significant moderation of this effect with a higher functional connectivity in $\mathrm{L}_{\mathrm{G}}$ or $\mathrm{S}$ allele carriers as compared to homozygous $\mathrm{L}_{\mathrm{A}}$ allele individuals. Walsh et al. (2012) did not only find increased left amygdala activation in $\mathrm{S}$ allele homozygous as compared to L allele homozygous subjects, but they also found an additive effect of recent negative life events and genotype on the left amygdala. Wiggins et al. (2014) were the only authors detecting differences in behavioural data associated with 5-HTT genotype in a neuroimaging study. During gender discrimination of emotional facial expressions, low-expressing individuals ( $\mathrm{S}$ or $\mathrm{L}_{\mathrm{G}}$ allele) had significantly shorter reaction times and showed both, significant increase in amygdala activation, as well as steeper decreases in right amygdala-left ventromedial PFC connectivity with increasing age. The right amygdala to right ventromedial PFC connectivity was predicted by the genotype-by-age interaction on a trend level. Removing the variance in reaction time and regardless of applying bi- or triallelic genotype grouping, the authors' hypotheses were still confirmed.

Summing up, studies applying the gender recognition task tended to reveal an $\mathrm{S}$ allele-associated heightened amygdala and ACC activation, while amygdala-MPFC functional coupling was decreased in $\mathrm{S}$ allele carriers. Having looked at studies using the most common face paradigms, results from more heterogenious task designs will be reviewed in the following.

Investigating Asian women with a passive viewing paradigm, Lee and Ham (2008) found bilaterally increased amygdala activation in $\mathrm{L}$ allele carriers as compared to $\mathrm{S}$ allele homozygous individuals during the angry vs. neutral faces contrast. Interestingly, this study reveals the opposite allele effect direction, suggesting the importance to get a deeper understanding of genetic effects depending on ethnicity.

Using fMRI and skin conductance response (SCR) measurement, Lonsdorf et al. (2011) investigated brain activation over time (early vs. late phase). They found 5-HTTLPR S allele carriers to have higher SCR habituation as compared to homozygous L allele car- 
riers, both showing SCR habituation over time. While passively viewing angry faces, $\mathrm{S}$ allele carriers had increased right amygdala activation as compared to homozygous L allele carriers during both phases. Homozygous L allele carriers showed greater right amygdala activation especially for the early as compared to the late phase. The authors interpreted this finding as a stronger amygdala habituation in homozygous L allele carriers. Analyzing whole brain level, homozygous L allele carriers revealed more left subgenual ACC activity in the early phase while processing angry faces. In an fMRI task by Surguladze et al. (2012), participants passively watched facial expressions changing from neutral to emotional. Analyzing 5-HTTLPR (incl. rs25531) polymorphisms, they grouped the allele carriers in low activity ( 5 -HTTLPR $\left.S+\operatorname{rs} 25531 \mathrm{~L}_{\mathrm{G}}=\mathrm{S}^{\prime}\right)$ and high activity alleles $\left(\mathrm{L}+\mathrm{L}_{\mathrm{A}}=\mathrm{L}^{\prime}\right)$. During fearful expressions, right amygdala activation was increased in low activity polymorphism carriers (S's'> L'L'), but not significantly. The number of $S^{\prime}$ alleles was reported to be significantly negatively correlated with total effective connectivity of a general emotion-processing circuit (encompassing the amygdala and the inferior frontal gyrus among other regions) in the fearful emotion processing condition (in the two contrasts: L'/L'vs. L'/S'and L'/L'vs. S'/S'). Volman et al. (2013) found a genotype ( $\mathrm{S}>\mathrm{L} / \mathrm{L}$ carriers) $\mathrm{x}$ condition effect on a trendlevel in an Approach-Avoidance Task, in which participants had to decide if they would approach or avoid a displayed face. In this study, gender recognition served only as control condition. S allele subjects showed greater amygdala activity during the angry faces condition. Non-S allele carriers exhibited negatively weighted connectivity between amygdala and anterior PFC (BA 10), whereas $S$ allele carriers did not differ from zero. The authors discussed their findings as a reduction of inhibitory PFC-amygdala control in S allele carriers, resulting in an amygdala disinhibition. In 2010, Dannlowski et al. (2010) used an fMRI task in which participants saw an emotional prime face before evaluating a following neutral face as rather positive or negative. They found risk allele carriers ( $\mathrm{S}$ or $\mathrm{L}_{\mathrm{G}}$ ) as compared to homozygous $\mathrm{L}_{\mathrm{A}}$ allele carriers showing increased right amygdala responsiveness to sad faces. In a study by Dannlowski and colleagues investigating healthy individuals and major depression patients, no significant allele effect on brain activation during passively viewing emotional faces was found in the healthy control group (Dannlowski et al., 2008). Thomason et al. (2010) investigated differences between sub- and supraliminal emotional stimulation in a dot-probe-task (indicating the side of an asterisk displayed after two faces presented side-by-side) investigating children. S allele carriers showed higher right ACC activation during subliminal angry facial expressions (vs. neutral faces). Letting participants respond whether an emotional face displayed was shifted to any side in an implicit emotion processing task, Von dem Hagen et al. (2011) found significantly higher bilateral amygdala activiation in $\mathrm{S}$ allele subjects in response to angry and sad facial expressions as compared to L allele homozygotes. This amygdala activity was found indepentently of using neutral faces or houses as baseline condition. However, contrasts with passively watching a fixation cross as baseline condition were not assoiated with genotype-dependent effects on amygdala activation during emotional face processing. Waring et al. (2014) showed participants pictures of emotional facial expressions overlayed with the words "happy" or "fear" which were congruent or incongruent with the facial emotion. The subjects had to identify the emotional expression while ignoring the word (to measure conflict regulation). While not reporting effects on activation, the authors found reduced dorsal ACC-perigenual ACC connectivity in S allele carriers as compared to L allele homozygous subjects related to higher conflict regulation. The authors interpreted their finding as an impaired emotional conflict adaption in S allele carriers.

In summary, most of these studies also revealed $\mathrm{S}$ alleleassociated increased amygdala and ACC activation and decreased coupling of amygdala and MPFC/ACC (for a studies overview, see Table 1).

Concerning 5-HTTLPR S allele-associated amygdala responsiveness, Canli and Lesch introduced a differentiation based on phasic versus tonic activation (Canli and Lesch, 2007). The phasic or standard model posits the $S$ allele being associated with elevated amygdala excitation in response to briefly presented or phasic negative stimuli. The tonic model approach posits greater negative emotionality coming along with an increased baseline activation of the amygdala in $\mathrm{S}$ allele carriers as compared with noncarriers (Canli and Lesch, 2007). Regarding the 5-HTTLPR imaging genetics studies reviewed in here, only three studies explicitly discussed their findings in light of the tonic-phasic differentiation (Canli et al., 2006; Von dem Hagen et al., 2011; Walsh et al., 2012). Canli and colleagues found a negative correlation between life stress and amygdala activation in response to neutral faces in comparison to a fixation cross condition. Furthermore, they measured absolute cerebral blood flow at rest using perfusion imaging. They observed higher amygdala perfusion levels at rest in S allele carriers as compared to homozygous L allele carriers. Due to this, they interpreted their findings as in line with and confirming the tonic model. Von dem Hagen and colleagues compared $S$ allele-driven amygdala activation in response to emotional facial expression with different baseline conditions (neutral faces, houses, fixation cross) (Von dem Hagen et al., 2011). Since they found no significant difference between direct comparisons of the baseline conditions, but in response to emotional faces in contrast to each of the baseline conditions, they interpreted their findings as in accordance to the phasic model. Walsh and colleagues reported $\mathrm{S}$ allele-associated amygdala activation in response to emotional faces and neutral faces in comparison to the fixation cross (Walsh et al., 2012). They regard their findings as being explained by the phasic rather than the tonic model. They argue that studies advocating the tonic model have generally applied block designs and longer fixation blocks possibly increasing unconstrained cognitive activity leading to increased baseline amygdala activity in S allele carriers. However, since the number of studies investigating 5-HTTLPR allele-associated amygdala responsivity to emotional faces taking resting state or baseline amygdala activation into account is too small, further studies will be necessary to resolve the tonic-phasic discrepancy. For a better understanding of the 5-HTTLPR-associated findings in this review, we will in the following sections focus on comparisons to imaging studies investigating the serotonin system in different ways in search for a more neurochemical model.

From a molecular or neurochemical perspective, interpreting gene polymorphism effects in fMRI experiments in humans is still theoretical to date, because no actual transmitter level is measured in real-time in the brain of the participant. One step to narrow this gap might be having a look at pharmacological challenge or substance abuse fMRI studies, since psychotropic drugs have a direct or indirect impact on the mechanism of action or the blood level of a neurotransmitter, e.g., acute tryptophan depletion or serotonin reputake inhibitors (SSRIs).

Therefore, the following part of our review concentrates on serotonin-related pharmacologic challenge fMRI studies investigating emotional face processing. Subsequently, we evaluate the results from the imaging genetics and pharmacological challenge studies in the light of neurochemical and molecular transmitter level findings from animal and further neuroimaging literature. 
Table 1

Imaging studies on 5-HTTLPR genotype effects on corticolimbic activation in association with emotional face processing.

\begin{tabular}{|c|c|c|c|c|}
\hline Reference & Sample (n) & Polymorphisms & Faces Task & Findings \\
\hline Bastiaansen et al. (2014) & 120 & 5-HTTLPR & Face matching & $\begin{array}{l}\text { No significant effect in the contrast } \mathrm{S}>\mathrm{LL} \\
\text { carriers. }\end{array}$ \\
\hline Battaglia et al. (2012) & 19 & 5-HTTLPR & Gender recognition & $\begin{array}{l}\text { S allele was associated with heightened left } \\
\text { amygdala response to angry but not neutral or } \\
\text { happy facial expressions. }\end{array}$ \\
\hline Bertolino et al. (2005) & 28 (14 PB, 14 EDP) & 5-HTTLPR & Face matching & $\begin{array}{l}\text { The number of } S \text { alleles as well as the degree of } \\
\text { phobia proneness predicted response in right } \\
\text { amygdala. }\end{array}$ \\
\hline Canli et al. (2006) & fMRI: $n=48 ;$ aCBF: $n=21$ & 5-HTTLPR & Gender recognition & $\begin{array}{l}\text { Negative correlation between life stress and } \\
\text { amygdala response to happy and neutral facial } \\
\text { stimuli (> fixation cross) as compared to } \\
\text { fixation cross in S as compared to homozygous } \\
\text { L allele carriers. Positive correlation in the L/L } \\
\text { group. Significant gene x environment effect on } \\
\text { gray matter volume in left amygdala positively } \\
\text { correlated with life stress in L homozygotes. } \\
\text { Elevated aCBF in amygdala at rest in S allele } \\
\text { carriers as compared to L/L carriers. }\end{array}$ \\
\hline Canli et al. (2008) & 49 & 5-HTTLPR, TPH2 rs4570625 & Gender recognition & $\begin{array}{l}\text { Increased amygdala activation in response to } \\
\text { fearful and sad faces associated with S and T } \\
\text { alleles. At the whole-brain level, increased } \\
\text { right ACC activation during happy faces also } \\
\text { associated S and T alleles. }\end{array}$ \\
\hline Costafreda et al. (2013) & $\mathrm{HC}, \mathrm{n}=49 ; \mathrm{MDD}, \mathrm{n}=67$ & 5-HTTLPR, rs25531 & Gender recognition & $\begin{array}{l}\text { No significant interaction effect of } 5 \text { HTTLPR } \\
\text { genotype and diagnosis was found. }\end{array}$ \\
\hline Dannlowski et al. (2008) & $\mathrm{HC}, \mathrm{n}=28 ; \mathrm{MDD}, \mathrm{n}=28$ & 5-HTTLPR, rs25531 & Passively viewing & $\begin{array}{l}\text { No significant allele effect was found in } \\
\text { healthy individuals. }\end{array}$ \\
\hline Dannlowski et al. (2010) & 44 & 5-HTTLPR, rs25531 & Emotional prime detection & $\begin{array}{l}\text { Risk allele carriers ( } \mathrm{S} \text { or } \mathrm{L}_{\mathrm{G}} \text { ) showed significant } \\
\text { increased right amygdala responsiveness to } \\
\text { sad faces, as compared to homozygous } \mathrm{L}_{\mathrm{A}} \\
\text { carriers. }\end{array}$ \\
\hline Domschke et al. (2012) & 85 & $\begin{array}{l}\text { 5-HTTLPR, rs25531, COMT } \\
\text { rs4680 }\end{array}$ & Face matching & $\begin{array}{l}\text { Increasing amygdala responsiveness with } \\
\text { number of } \mathrm{S} \text { alleles. }\end{array}$ \\
\hline Fisher et al. (2014) & 30 & 5-HTTLPR, rs25531 & Gender recognition & $\begin{array}{l}\text { Increased intraprefrontal functional coupling } \\
\text { of medial PFC after bright-light intervention in } \\
\mathrm{LG} \text { or } \mathrm{S} \text { carriers. Little effect was observed in } \\
\mathrm{L}_{\mathrm{A}} / \mathrm{L}_{\mathrm{A}} \text { carriers. }\end{array}$ \\
\hline Fisher et al. (2015) & 76 & 5-HTTLPR, rs25531 & Gender recognition & $\begin{array}{l}\text { Homozygous } \mathrm{L}_{\mathrm{A}} \text { carriers showed increased } \\
\text { response in bilateral amygdala and frontal } \\
\text { cortical areas in response to angry faces. } \mathrm{S}^{\prime} \\
\text { individuals had increased activity of these } \\
\text { areas during angry and fearful faces vs. neutral. } \\
\mathrm{L}_{\mathrm{A}} / \mathrm{L}_{\mathrm{A}} \text { individuals showed a higher response to } \\
\text { angry faces as compared to } \mathrm{S}^{\prime} \text { carriers. } \mathrm{S}^{\prime} \\
\text { individuals showed a greater response to } \\
\text { fearful faces as compared to homozygous } \mathrm{L}_{\mathrm{A}} \\
\text { carriers. }\end{array}$ \\
\hline Hariri et al. (2002) & 28 & 5-HTTLPR & Face matching & $\begin{array}{l}\text { S allele carriers exhibit an increased right } \\
\text { amygdala response to fearful stimuli compared } \\
\text { with homozygous L allele carriers. }\end{array}$ \\
\hline Hariri et al. (2005) & 92 & 5-HTTLPR & Face matching & $\begin{array}{l}\text { Activity of the right amygdala was significantly } \\
\text { greater in S allele carriers in comparison with L } \\
\text { allele homozygous. Additional analyses } \\
\text { indicated that the 5-HTTLPR effect on right } \\
\text { amygdala activity was independent of both sex } \\
\text { and S allele load. }\end{array}$ \\
\hline Lee and Ham (2008) & 54 & 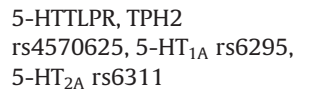 & Passively viewing & $\begin{array}{l}\text { Bilateral amygdala activation in L allele } \\
\text { carriers as compared to } \mathrm{S} \text { homozygous } \\
\text { individuals during angry vs. neutral faces. }\end{array}$ \\
\hline Lonsdorf et al. (2011) & 54 & 5-HTTLPR, COMT rs4680 & Passively viewing & $\begin{array}{l}\text { S allele carriers had higher SCR habituation as } \\
\text { compared to L/L carriers. While watching angry } \\
\text { faces, } \mathrm{S} \text { carriers had increased right amygdala } \\
\text { activation as compared to L/L carriers during } \\
\text { early and late phase. } \mathrm{L} / \mathrm{L} \text { carriers showed } \\
\text { increased right amygdala activation especially } \\
\text { in early phase. At whole-brain level, L/L } \\
\text { carriers showed higher left sgACC activation in } \\
\text { early phase while processing angry faces. }\end{array}$ \\
\hline O'Nions et al. (2011) & 30 & 5-HTTLPR, rs25531 & Gender recognition & $\begin{array}{l}\text { In } \mathrm{L}_{\mathrm{A}} / \mathrm{L}_{\mathrm{A}} \text { subjects the subgenual ACC response } \\
\text { was decreased for fearful relative to neutral } \\
\text { faces, and was increased in the } S / S \text { group. }\end{array}$ \\
\hline
\end{tabular}


Table 1 (Continued)

\begin{tabular}{|c|c|c|c|c|}
\hline Reference & Sample (n) & Polymorphisms & Faces Task & Findings \\
\hline Pezawas et al. (2005) & sMRI: $\mathrm{n}=114 ;$ fMRI: $\mathrm{n}=94$ & 5-HTTLPR & Face matching & $\begin{array}{l}\text { In comparison to L/L subjects, S allele carriers } \\
\text { showed significantly reduced volume of the } \\
\text { pACC and right amygdala. Short allele carriers } \\
\text { showed a highly significant reduction of } \\
\text { amygdala-pACC connectivity in comparison to } \\
\text { L/L genotype individuals, especiallyly in rACC. } \\
\text { The functional coupling between amygdala } \\
\text { and ventromedial PFC was weakly increased. }\end{array}$ \\
\hline Surguladze et al. (2008) & 29 & 5-HTTLPR & Gender recognition & $\begin{array}{l}\text { Increased functional coupling between } \\
\text { amygdala and right FG in S/S carriers during } \\
\text { prototypical fearful faces as compared to S/L or } \\
\text { L/L carriers. }\end{array}$ \\
\hline Surguladze et al. (2012) & 91 & $\begin{array}{l}\text { 5-HTTLPR, rs25531, } \\
\text { COMT rs } 4680\end{array}$ & Passively viewing dynamic faces & $\begin{array}{l}\text { While fearful faces, right amygdala activation } \\
\text { was increased in S'/S'> L'/L' carriers, but not } \\
\text { significantly. S' allele number was inversely } \\
\text { correlated with total effective connectivity of a } \\
\text { general emotion-processing circuit } \\
\text { (encompassing amygdala) during fearful faces. }\end{array}$ \\
\hline Thomason et al. (2010) & 51 & 5-HTTLPR, rs25531 & Dot-Probe-Task & $\begin{array}{l}\text { S carriers showed more right ACC activation } \\
\text { during subliminal angry > neutral contrast as } \\
\text { compared to L-homozygous. }\end{array}$ \\
\hline Volman et al. (2013) & 48 & 5-HTTLPR & Approach-Avoidance-Task & $\begin{array}{l}\text { S carriers showed higher amygdala activation } \\
\text { during the angry faces condition. } \\
\text { Amygdala-anterior PFC functional coupling } \\
\text { was negatively weighted in non-S carriers. }\end{array}$ \\
\hline Von dem Hagen et al. (2011) & 68 & 5-HTTLPR & Face shift recognition & $\begin{array}{l}\text { S carriers exhibited higher bilateral amygdala } \\
\text { activation in response to angry and sad facial } \\
\text { expressions. }\end{array}$ \\
\hline Walsh et al. (2012) & 67 & 5-HTTLPR & Gender recognition & $\begin{array}{l}\text { Left amygdala showed increased activation in } \\
\text { S/S carriers as compared to L/L carriers. } \\
\text { Additive effect of recent negative life events } \\
\text { and genotype on left amygdala activation. }\end{array}$ \\
\hline Waring et al. (2014) & 29 & 5-HTTLPR & Emotional conflict regulation & $\begin{array}{l}\text { As compared to L/L carriers, S carriers showed } \\
\text { decreased functional connectivity between } \\
\text { dorsal and pACC associated with impaired } \\
\text { conflict regulation. }\end{array}$ \\
\hline Wiggins et al. (2014) & 48 & 5-HTTLPR, rs25531 & Gender recognition & $\begin{array}{l}\mathrm{S} \text { or } \mathrm{L}_{\mathrm{G}} \text { carriers showed shorter RT. Low } \\
\text { expressing group showed increased amygdala } \\
\text { activation and steeper right } \\
\text { amygdala-ventromedial PFC functional } \\
\text { connectivity with increasing age. Functional } \\
\text { connectivity was predicted by } \\
\text { genotype-by-age interaction (trend level). }\end{array}$ \\
\hline
\end{tabular}

$\mathrm{aCBF}=$ absolute cerebral blood flow; $\mathrm{COMT}=$ catechol-o-methyltransferase; $\mathrm{EDP}=$ eating disorders prone; $\mathrm{FG}=$ fusiform gyrus; $\mathrm{fMRI}=$ functional magnetic resonance imaging; $\mathrm{MDD}=$ major depressive disorder patients; $\mathrm{PACC}=$ perigenual anterior cingulate cortex; $\mathrm{PD}=$ phobia prone; $\mathrm{PFC}=$ prefrontal cortex; $\mathrm{rACC}=$ rostral subgenual anterior cingulate cortex; RT = reaction time; $\mathrm{SCR}=$ skin conductance response; $\mathrm{sgACC}=$ subgenual anterior cingulate cortex; sMRI = structural magnetic resonance imaging; TPH2 = tryptophan hydroxylase 2 .

\section{Functional neuroimaging of pharmacological challenge of the serotonin system}

Having a closer look at pharmacologic challenge imaging literature according to its impact on serotonin, relevant emotional face processing studies can be coarsely divided into two groups. The first group of relevant fMRI studies investigates healthy volunteers taking a psychopharmacologic agent (e.g., SSRI) in comparison to placebo during an emotional faces task. The second group of studies reports experiments modulating serotonin levels in healthy volunteers by depleting or elevating blood concentrations of tryptophan, a precursor of serotonin.

The systematic PubMed database search was conducted, using the search terms "serotonin", "serotonergic", "emotion recognition", "affect recognition", "emotion processing”, "affect processing", "face processing", "facial affect", "facial emotion", and "imaging" in combination with the keywords "antidepressant"; "tryptophan depletion" or "tryptophan elevation". The final search for this review was carried out in January 2016 and revealed a total of 83 publications. The search process revealed 13 fMRI studies fulfilling the inclusion criteria for the antidepressant group and 8 fMRI studies for the tryptophan group.

\subsection{Antidepressant treatment}

Most of the studies investigated agents inhibiting the presynaptic reuptake of serotonin from the synaptic cleft, so called selective serotonin-reuptake inhibitors (SSRIs), e.g., citalopram or escitalopram. In one study the extract of the plant Sceletium tortuosum (Zembrin), a dual serotonin-reuptake and PDE4 inhibitor, was given, another study tested the combined serotoninnorepinehrine-reuptake inhibitor duloxetine. All of these drugs are known to increase synaptic serotonin.

Ten studies used citalopram as pharmacologic agent (Anderson et al., 2007; Bigos et al., 2008; Del-Ben et al., 2005; Di Simplicio et al., 2014; Harmer et al., 2006; Klomp et al., 2013; Ma et al., 2015; Murphy et al., 2009; Norbury et al., 2009; Windischberger et al., 2010). Six of these 10 studies used a gender recognition task (Anderson et al., 2007; Del-Ben et al., 2005; Di Simplicio et al., 2014; Harmer et al., 2006; Klomp et al., 2013; Murphy et al., 2009). DelBen et al. (2005) found a decrease in right amygdala associated with aversive facial expression (anger, disgust, fear) after citalopram intake. Using the same task, the finding of an attenuated amygdala activation following citalopram could be replicated by three more studies (Anderson et al., 2007; Harmer et al., 2006; Murphy et al., 2009). Two studies reported an opposite effect, elevated amygdala 
responsivity to emotional facial gender recognition (Di Simplicio et al., 2014; Klomp et al., 2013). Further regions related to face processing have been found to be altered by citalopram effects. Two studies reported decreased lateral OFC activation associated with aversive facial expression after citalopram intake (Anderson et al., 2007; Del-Ben et al., 2005). An attenuated MPFC activation under citalopram was reported by Harmer et al. (2006). In addition, the authors found a decrease in the ability to recognize fearful facial expressions under citalopram. Murphy et al. (2009) found decreased medial frontal responsivity to fearful faces under citalopram as compared to placebo. In a recent fMRI and haemoperfusion study by Di Simplicio et al. (2014), healthy controls were grouped in high and low level neurotic and compared during citalopram vs. placebo treatment. Analyzed was the processing of happy and fearful faces. Under citalopram they found greater response to fearful as compared to happy faces in areas including paracingulate cortex and dorsal ACC specifically in participants with high level neuroticism. Two of the ten reviewed citalopram studies used an emotion matching task (Norbury et al., 2009; Windischberger et al., 2010). In an fMRI study by Norbury et al. (2009), bilateral amygdala activation increase in response to happy faces was observed under citalopram. The placebo group showed elevated bilateral amygdala activation related to fearful expressions. In an fMRI publication by Windischberger et al. (2010), both, citalopram and escitalopram, were tested during an emotional faces vs. geometric shape matching paradigm. Associated with both drugs, they found decreased right amygdala activation during face processing The placebo group showed stronger bilateral amygdala activation. Bilateral medial frontal activation decrease was observed under escitalopram exposure. Bigos et al. (2008) reported citalopram concentration-dependent bilateral amygdala activation increase during an emotion matching task. In a pharmaco-genetics fMRI study by Ma et al. (2015), citalopram was revealed to increase left amygdala activation during fearful faces processing in a repetitiondetection task. Furthermore, both amygdalae showed elevated activation during fearful faces processing in homozygous $\mathrm{L}$, but not homozygous S allele carriers. In line with the 5-HTTLPR imaging genetics studies reviewed above, the homozygous $\mathrm{S}$ allele carriers as compared to the homozygous L allele carriers in the placebo group revealed significantly stronger (left-sided) amygdala activation while viewing fearful faces.

Analyzing solely escitalopram effects, Arce et al. (2008) found decreases in bilateral amygdala and subgenual ACC activation associated with elevated escitalopram urine concentrations. Left amygdala responsivity to fearful faces was decreased under escitalopram, the same effect in response to angry faces was marginally significant. Terburg et al. (2013) published a study testing the dual SSRI and PDE4 inhibitor Zembrin during emotional face matching. They found heightened amygdala activation under Zembrin during emotion processing. Functional connectivity between amygdala and hypothalamus was decreased after Zembrin as compared to placebo administration, marginally larger in the emotional condition. The serotonin-norepinephrine-reuptake inhibitor duloxetine was used in a study by Van Marle et al. (2011). The group reported attenuated amygdala and ventral ACC activation under duloxetine during face-matching (>control condition). In addition to that, they found increased functional coupling between amygdala and anterior insula after duloxetine administration.

Summing up, despite some inconsistent findings the majority of studies reports decreased amygdala and decreased frontal or cingulate activation to emotional face stimuli under antidepressant (synaptic serotonin elevating) medication (for a more detailed overview, see Table 2).

\subsection{Acute tryptophan depletion (ATD)}

5-hydroxytryptophan emerges from the hydroxylation of the amino acid tryptophan. Serotonin is synthesized by decarboxylation of 5-hydroxytryptophan (Wurtman et al., 1980). Since only the precursors of serotonin can cross the blood-brain barrier, tryptophan levels can control the serotonin synthesis rate in the brain (Cansev and Wurtman, 2007; Pardridge, 1979). Subsequently, depleting tryptophan levels experimentally to lower the serotonin availabilty has become a common method to investigate the serotonergic function of the brain (Reilly et al., 1997). Since acute tryptophan depletion (ATD) has been applied in several emotion processing studies (for an excellent review on this topic, see Evers et al., 2010), the comparison of its serotonin-modulated brain activation and the 5-HTTLPR-related one during emotional face processing is of high interest. As ATD comes along with serotonin decrease, an opposing effect to SSRI treatment can be hypothesized.

We found eight articles fulfilling our inclusion criteria for ATD studies. Five of the eight ATD studies included in the review used a gender recognition task (Cools et al., 2005; Fusar-Poli et al., 2007; Grady et al., 2013; Passamonti et al., 2012; Van der Veen et al., 2007). Using this task, Cools et al. (2005) reported ATD-associated increased right amygdala activation predicted by threat-sensitivity during the processing of fearful faces. This finding of increased amygdala responsivity to emotional faces after ATD was replicated by three studies (Fusar-Poli et al., 2007; Grady et al., 2013; Van der Veen et al., 2007). However, one study could not replicate this effect (Passamonti et al., 2012). Grady and colleagues additionally observed bilateral increased amygdala activation under ATD as compared to serotonin increase by citalopram (Grady et al., 2013). Only Fusar-Poli and colleagues found an opposite effect, a decrease in left amygdala activation under ATD, in a combined happy and sad faces contrast (Fusar-Poli et al., 2007). Furthermore, several studies reported activation and connectivity related to other brain regions important for face processing. On whole-brain level, Van der Veen and colleagues found ATD-related increased right-sided ventromedial PFC activation overlapping with rostral ACC in the fearful vs. happy condition (Van der Veen et al., 2007). Grady and colleagues reported ATD-associated MPFC activation during processing angry and fearful faces (Grady et al., 2013). While not finding significant treatment-related activation, Passamonti and colleagues found increased effective connectivity between amygdala and ACC and between amygdala and ventrolateral PFC (VLPFC) associated with the processing of angry faces under ATD modulation (Passamonti et al., 2012).

In another fMRI study, Williams et al. (2007) found increased right amygdala activation during viewing happy faces and increased left amygdala responsivity associated with fearful face processing during an emotion recognition task. Both results were observed for the ATD group. Furthermore, they found increased ACC/MPFC activation associated with ATD during processing of frontally viewed faces as compared to faces shown from a sided perspectve. In a study by Robinson et al. (2013), only a trend for elevated amygdala activation during processing of fearful faces under ATD was observed using an emotional conflict regulation task. Additionally, activation of dorsal ACC and dorsal medial PFC was increased under ATD in the fearful faces condition as well. Regarding connectivity findings, Robinson et al. (2013) observed increased ACC/dorsal MPFC-amygdala connectivity during processing of fearful faces. In another fMRI study, Kroes and colleagues found no effect on brain activation by modulating the tryptophan blood plasma concentration during an emotion matching task (Kroes et al., 2014).

Taken together, the ATD imaging literature rather homogeniously suggests elevated amygdala activation. In addition, these findings suggest a prefrontal/cingulate activation increase and 
Table 2

Pharmacological imaging studies on antidepressant treatment effects on corticolimbic activation in association with emotional face processing.

\begin{tabular}{|c|c|c|c|c|}
\hline Reference & Sample (n) & Drug (period of treatment) & Faces Task & Findings \\
\hline Anderson et al. (2007) & 12 & citalopram (single dose) & Gender recognition & $\begin{array}{l}\text { Decreased left amygdala activation during disgust faces } \\
\text { and decreased right amygdala and right lateral OFC } \\
\text { activation related to fearful facial expressions under } \\
\text { citaloram. }\end{array}$ \\
\hline Arce et al. (2008) & 13 & escitalopram ( 21 days) & Emotion matching & $\begin{array}{l}\text { Decreases in bilateral amygdala and subgenual ACC } \\
\text { activation associated with elevated escitalopram urine } \\
\text { concentrations. Left amygdala responsivity to fearful faces } \\
\text { was decreased under escitalopram, the same effect in } \\
\text { response to angry faces was marginally significant. }\end{array}$ \\
\hline Bigos et al. (2008) & 8 & citalopram (single dose) & Face matching & $\begin{array}{l}\text { Citalopram concentration-dependent bilateral amygdala } \\
\text { activation increase. }\end{array}$ \\
\hline Del-Ben et al. (2005) & 12 & citalopram (single dose) & Gender recognition & $\begin{array}{l}\text { Decrease in right amygdala and right lateral OFC } \\
\text { responsivity associated with aversive facial expression } \\
\text { (anger, disgust, fear) }\end{array}$ \\
\hline Di Simplicio et al. (2014) & 48 & citalopram (7 days) & Gender recognition & $\begin{array}{l}\text { Healthy controls were grouped in high and low level } \\
\text { neurotic and compared during citalopram vs. placebo } \\
\text { treatment. Analyzed was the processing of happy and } \\
\text { fearful faces. Under citalopram they found greater } \\
\text { response to fearful as compared to happy faces in areas } \\
\text { including paracingulate cortex and dorsal ACC in } \\
\text { participants with high level neuroticism. Extracting mean } \\
\text { perfusion levels from the amgdalae, they observed a } \\
\text { citalopram-associated increased right amygdala perfusion. } \\
\text { Regardless of emotion increased bilateral amygdala } \\
\text { activation was found under citalopram as compared to } \\
\text { placebo during face processing. }\end{array}$ \\
\hline Harmer et al. (2006) & 24 & citalopram ( 7 days) & Gender recognition & $\begin{array}{l}\text { In relation to fearful faces, attenuated bilateral amygdala } \\
\text { and MPFC activation under citalopram. Additionally, a } \\
\text { decrease in the ability to recognize fearful facial } \\
\text { expressions under citalopram. }\end{array}$ \\
\hline Klomp et al. (2013) & 12 & citalopram (single dose) & Gender recognition & $\begin{array}{l}\text { Participants were scanned twice. During the second scan } \\
\text { increased medial frontal and paracingulate activation was } \\
\text { revealed suggesting a citalopram effect. When they } \\
\text { directly compared the citalopram scans and its preceding } \\
\text { baseline scan, a positive effect of citalopram on amygdala } \\
\text { activation increase was revealed during the second scan } \\
\text { session while processing emotional faces. }\end{array}$ \\
\hline Ma et al. (2015) & 46 & citalopram (single dose) & Repetition-detection task & $\begin{array}{l}\text { The placebo group revealed significantly stronger left } \\
\text { amygdala in S/S than } \mathrm{L} / \mathrm{L} \text { carriers in fearful > neutral } \\
\text { contrast; citalopram increased left amygdala activation } \\
\text { during fearful; acute administration of citalopram } \\
\text { increased response in the left and right amygdala to fearful } \\
\text { vs. neutral faces in L/L, but not S/S carriers; no effect } \\
\text { related to happy faces. }\end{array}$ \\
\hline Murphy et al. (2009) & 26 & citalopram (single dose) & Gender recognition & $\begin{array}{l}\text { Decreased right amygdala and medial frontal responsivity } \\
\text { to fearful faces under citalopram as compared to placebo }\end{array}$ \\
\hline Norbury et al. (2009) & 28 & citalopram (7-10 days) & Emotion matching & $\begin{array}{l}\text { Bilateral amygdala activation increase in response to } \\
\text { happy faces under citalopram. The placebo group showed } \\
\text { elevated bilateral amygdala activation related to fearful } \\
\text { expressions. }\end{array}$ \\
\hline Terburg et al. (2013) & 16 & Zembrin (single dose) & Emotion matching & $\begin{array}{l}\text { Heightened amygdala activation under Zembrin during } \\
\text { emotion processing. Functional connectivity between } \\
\text { amygdala and hypothalamus was decreased after Zembrin } \\
\text { as compared to placebo administration, marginally larger } \\
\text { in the emotional condition. }\end{array}$ \\
\hline Van Marle et al. (2011) & 19 & duloxetine (14 days) & Face matching & $\begin{array}{l}\text { Attenuated amygdala and ventral ACC activation under } \\
\text { duloxetine during face-matching (>control condition). In } \\
\text { addition, increased functional coupling between amygdala } \\
\text { and anterior insula after duloxetine administration. }\end{array}$ \\
\hline Windischberger et al. (2010) & 18 & citalopram, escitalopram (10 days) & Emotion matching & $\begin{array}{l}\text { Citalopram and escitalopram were tested during an } \\
\text { emotional faces vs. geometric shape matching paradigm. } \\
\text { Associated with both drugs, they found decreased right } \\
\text { amygdala activation during face processing. The placebo } \\
\text { group showed elevated bilateral amygdala activation. } \\
\text { Bilateral medial frontal activation decrease was observed } \\
\text { under escitalopram exposure. }\end{array}$ \\
\hline
\end{tabular}

$\mathrm{ACC}=$ anterior cingulate cortex; $\mathrm{MPFC}=$ medial prefrontal cortex; $\mathrm{OFC}=$ orbitofrontal cortex.

intensified amygdala-prefrontal coupling, if less brain serotonin is available (for an overview of studies, see Table 3).

\section{Serotonin modulation at the neurochemical level}

The purpose of this review is to provide an overview of imaging studies on emotional face processing, investigating genetic effects 
Table 3

Imaging studies on tryptophan modulation effects on corticolimbic activation in association with emotional face processing.

\begin{tabular}{|c|c|c|c|c|}
\hline Reference & Sample (n) & TRP modulation & Faces Task & Findings \\
\hline Cools et al. (2005) & 12 & ATD & Gender recognition & $\begin{array}{l}\text { ATD-associated increased right } \\
\text { amygdala activation predicted by } \\
\text { threat-sensitivity during processing of } \\
\text { fearful faces. This finding could be } \\
\text { replicated by Van der Veen et al. } \\
\text { (2007). }\end{array}$ \\
\hline Fusar-Poli et al. (2007) & 10 & ATD & Gender recognition & $\begin{array}{l}\text { Decreased left amygdala activation } \\
\text { under ATD in a combined happy and } \\
\text { sad faces contrasts and increased right } \\
\text { amygdala responsivity associated with } \\
\text { ATD as compared to serotonin } \\
\text { elevation using a balanced } \\
\text { tryptophan-containing amino acid } \\
\text { mixture. }\end{array}$ \\
\hline Grady et al. (2013) & 20 & ATD citalopram & Gender recognition & $\begin{array}{l}\text { ATD-associated enhanced left } \\
\text { amygdala and MPFC activation during } \\
\text { processing angry and fearful faces. } \\
\text { They additionally observed bilateral } \\
\text { increased amygdala activation under } \\
\text { ATD as compared to serotonin increase } \\
\text { by citalopram. }\end{array}$ \\
\hline Kroes et al. (2014) & 32 & TRP/LNAA ratio modulated drink & Emotion matching & $\begin{array}{l}\text { No effect of test-drink consumption on } \\
\text { neural responses to emotional face } \\
\text { processing. }\end{array}$ \\
\hline Passamonti et al. (2012) & 19 & ATD & Gender recognition & $\begin{array}{l}\text { Increased effective connectivity } \\
\text { bewteen amygdala and ACC and } \\
\text { amygdala and VLPFC associated with } \\
\text { the processing of angry faces under } \\
\text { ATD modulation. }\end{array}$ \\
\hline Robinson et al. (2013) & 19 & ATD & Emotional conflict regulation & $\begin{array}{l}\text { Trend for elevated amygdala activation } \\
\text { during processing of fearful faces } \\
\text { under ATD. Additionally, activation of } \\
\text { dorsal ACC and dorsal medial PFC was } \\
\text { increased under ATD in the fearful } \\
\text { faces condition. Furthermore, under } \\
\text { ATD increased ACC/dorsal } \\
\text { MPFC-amygdala connectivity during } \\
\text { processing of fearful faces. }\end{array}$ \\
\hline Van der Veen et al. (2007) & 24 & ATD & Emotion intensity recognition Gender recognition & $\begin{array}{l}\text { Replication of the findings by Cools } \\
\text { et al. (2005). On whole-brain level, the } \\
\text { authors additionally found ATD-related } \\
\text { increased right-sided ventromedial } \\
\text { PFC activation overlapping with rostral } \\
\text { ACC in the fearful vs. happy condition. }\end{array}$ \\
\hline Williams et al. (2007) & 10 & ATD & Emotion recognition (different face positions) & $\begin{array}{l}\text { Increased right amygdala activation } \\
\text { during viewing happy faces and } \\
\text { increased left amygdala responsivity } \\
\text { associated with fearful face processing. } \\
\text { Both results were observed for the ATD } \\
\text { group. Furthermore, they found } \\
\text { increased ACC/MPFC activation } \\
\text { associated with ATD during processing } \\
\text { of frontally viewed faces as compared } \\
\text { to faces shown from a sided } \\
\text { perspectve. }\end{array}$ \\
\hline
\end{tabular}

ATD = acute tryptophan depletion; LNAA = long neutral amino acids; valine, isoleucine, leucine, tyrosine, and phenylalanine; TRP = tryptophan.

of the 5-HTTLPR polymorphism as well as pharmacologic effects of tryptophan-level and antidepressant serotonergic modulation. The online database search was focused on studies in healthy volunteers and restricted to impact on neural circuitry encompassing amygdala, OFC, ACC, and MPFC. In the first part of this review, neuroimaging studies on 5-HTTLPR have been reported, with their results indicating specific tendencies in their overall brain activation patterns, indirectly modulated at the transmitter level due to the genetic variation. For connecting the dots between the genetic and the neurotransmitter level in the second part of this review, we conducted an additional systematic search for imaging studies which investigated the influence of direct transmitter modulation, comparing pharmacologically challenged healthy individuals. Our interest was to see if there are similarities or differences in brain activation regarding the pharmacologically facilitated serotonergic state as compared with the imaging genetics results. However, the challenge studies revealed partially contradictory results in comparison to the imaging genetics findings. In the following third part, we evaluate these different imaging studies in light of recent neurobiological evidence, trying to bridge the gap between neuroimaging findings of imaging genetics and challenge studies. For this purpose, first challenge studies and then the imaging genetics studies will be discussed to provide a comprehensive model of serotonin effects on brain activation in response to facial expressions (for an overview on the effects found by all 46 reviewed neuroimaging studies, see Fig. 1). 


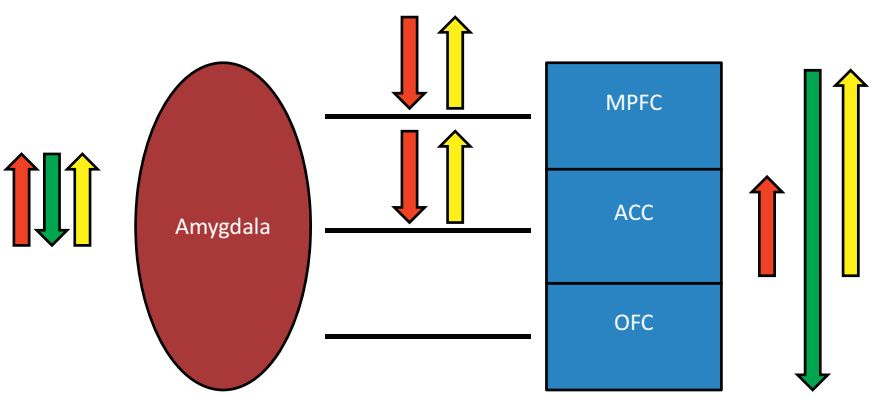

Fig. 1. Effects of 5-HTTLPR S allele (red arrow), pharmacological serotonin reuptake inhibition (green arrow) and acute tryptophan depletion (yellow arrow) on amygdalo-(pre-)frontal activation and functional connectivity (black horizontal line) during aversive facial emotion processing; direction of the arrow indicates the direction of the effect (enhancing versus decreasing); length of the arrow indicates the related frontal or cingulate cortex areas; $M P F C=$ medial prefrontal cortex, $\mathrm{ACC}=$ anterior cingulate cortex, $\mathrm{OFC}=$ orbitofrontal cortex, arrows up $/$ down $=$ increase $/$ decrease

\subsection{Antidepressant treatment studies}

The functional imaging studies on antidepressant serotoninreuptake inhibiting drugs revealed a tendency to hypoactivated amygdala, frontal and cingulate cortex under medication (serotonin elevated).

Regarding pharmacologic serotonin-reuptake inhibition, the in-vivo microdialysis studies have shown that the inhibition of serotonin reuptake produced by single administration of tricyclic antidepressants and SSRIs caused a significant elevation of the extracellular serotonin concentration in the midbrain raphe nuclei of rodents (Adell and Artigas, 1991; Bel and Artigas, 1992; Invernizzi et al., 1992). This extracellular serotonin increase in the midbrain raphe nuclei has been observed to activate inhibitory 5$\mathrm{HT}_{1 \mathrm{~A}}$ autoreceptors which leads to a reduction in 5-HT firing in the forebrain (Artigas, 2013; Artigas et al., 1996; Blier and de Montigny, 1994; Romero et al., 1996). For humans, Fisher et al. (2006) could show an inverse relationship between $5-\mathrm{HT}_{1 \mathrm{~A}}$ autoreceptor density in dorsal raphe nuclei and threat-related amygdala activation using a combined fMRI-PET approach. The authors hypothesized a $5-\mathrm{HT}_{1 \mathrm{~A}}$ receptor-mediated loss of negative feedback regulation, leading to disinhibited arousal of the amygdala. The other way round, the conclusion that increased $5-\mathrm{HT}_{1 \mathrm{~A}}$ density and activation are associated with decreased amygdala activation can be drawn. Thus, drug-induced 5- $\mathrm{HT}_{1 \mathrm{~A}}$ receptor activation might be an explanation for decreased corticolimbic signaling in participants treated with serotonin-reuptake inhibiting antidepressants during emotional face processing (see Fig. 2).

Chronic treatment with serotonin-reuptake inhibiting drugs has been observed to come along with neuronal adaption processes. Bel and Artigas reported a transient increase in extracellular serotonin in the frontal cortex of the rat after acute SSRI administration (Bel and Artigas, 1993). As compared to that, they found a six times higher frontal extracellular serotonin increase after a continuous infusion of the same SSRI over a period of 14 days. This is explained by a desensitization of the $5-\mathrm{HT}_{1 \mathrm{~A}}$ receptor due to a chronic SSRI treatment (Blier et al., 1990; Celada et al., 2004; El Mansari et al., 2005; Hervás et al., 2001). The desensitization allows more serotonin to be released per impulse reaching the nerve terminals (Blier and de Montigny, 1994). This suggests that different periods of pharmacologic antidepressant treatment might lead to different corticolimbic activational patterns, e.g., increased corticolimbic activation after chronic as compared to single dose treatment. The antidepressant challenge studies reviewed in here partially dif-
Antidepressant serotonin-reuptake inhibition and ATD effects

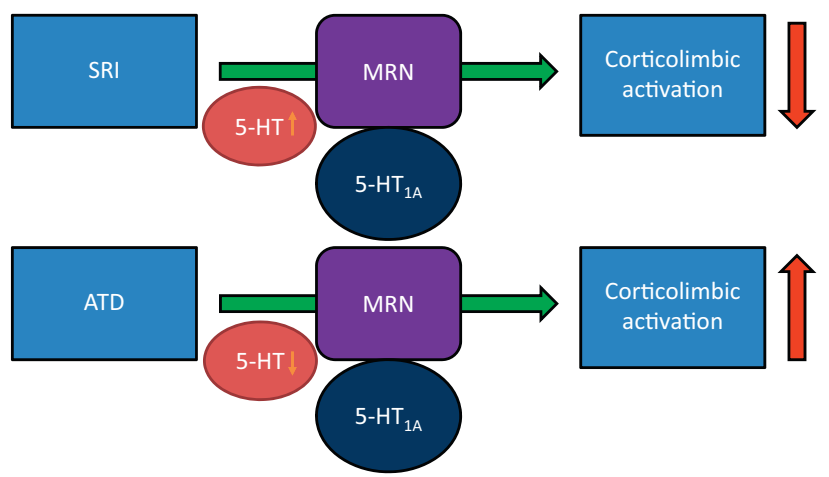

Fig. 2. Effects of pharmacologic challenge on corticolimbic activation (red arrow) during emotional face processing driven by $5-\mathrm{HT}_{1 \mathrm{~A}}$ receptor signaling in midbrain raphe nuclei area; 5-HT= serotonin concentration altered by SRI or ATD (orange arrow); $5-\mathrm{HT}_{1 \mathrm{~A}}$ receptors; $\mathrm{ATD}=$ acute tryptophan depletion; $\mathrm{MRN}=$ midbrain raphe nuclei; SRI = serotonin-reuptake inhibition by pharmacologic antidepressant drug; arrows up/down $=$ increase $/$ decrease.

fer in the periods of drug administration as follows: single-dose (Anderson et al., 2007; Bigos et al., 2008; Del-Ben et al., 2005; Klomp et al., 2013; Ma et al., 2015; Murphy et al., 2009; Terburg et al., 2013), 7 days (Di Simplicio et al., 2014; Harmer et al., 2006), 7-10 days (Norbury et al., 2009), 10 days (Windischberger et al., 2010), 14 days (Van Marle et al., 2011), and 21 days (Arce et al., 2008). Unfortunately, the reviewed imaging studies do not allow conclusions about effects of the length of the treatment period due to inconsistent results. Therefore, further investigations are needed.

\subsection{ATD studies}

The imaging results of the tryptophan experiments suggest an ATD-mediated amygdala and prefrontal/cingulate activation increase and intensified coupling (serotonin attenuated).

Despite a controversy about the exact neurobiological effect of ATD on serotonin (Van Donkelaar et al., 2011; Young, 2013), several studies have revealed a decrease in plasma tryptophan levels following ATD in animals (e.g., Blokland et al., 2002; Lieben et al., 2004) and humans (e.g., Reilly et al., 1997; Van der Does, 2001). Furthermore, a reduction in levels of the 5-HT metabolite 5hydroxyindoleacetic (5-HIAA) in human cerebrospinal fluid (CSF) has been found after ATD (e.g., Carpenter et al., 1998; Moreno et al., 2000; Williams et al., 1999).

Using positron emission tomography (PET) in humans, Nishizawa and colleagues could demonstrate a reduction in serotonin synthesis after ATD in different cerebral areas, e.g., the frontal cortex and the amygdala (Nishizawa et al., 1997). Detecting a cortisol response in depressed patients after ATD as compared to after a control amino acid mixture in a study by Price and colleagues, a regulatory function of 5-HT receptors was suggested (Price et al., 1998). In another study, Price and colleagues investigated the cortisol response in depressed patients after having the serotonergic agonist $\mathrm{m}$-chlorophenylpiperazine infused following ATD (Price et al., 1997). The results were similar to the other study, suggesting compensatory upregulation of $5-\mathrm{HT}_{2 \mathrm{~A} / 2 \mathrm{C}}$ receptors. In an animal study, Cahir and colleagues observed an elevated cortical 5- $\mathrm{HT}_{2 \mathrm{~A}}$ receptor binding in the rat brain after three weeks of tryptophan decrease (Cahir et al., 2007), indicating a compensatory upregulation in response to serotonin deficiency. Interestingly, Cahir and colleagues additionally reported a reduction in $5-\mathrm{HT}_{1 \mathrm{~A}}$ autoreceptor binding in raphe nuclei after ATD, while not alter- 
ing cortico-limbic binding sites, suggesting a reduced serotonergic feedback modulation in the raphe nuclei area (Cahir et al., 2007). This diminished inhibitory feedback loop after ATD might account for an increased corticolimbic activation during emotion processing as observed in the ATD studies reviewed in here (see Fig. 2). However, further studies on differences between effects of acute and chronic tryptophan depletion on serotonin receptors are needed.

\subsection{5-HTTLPR studies}

Looking at the 5-HTTLPR neuroimaging publications, the results indicate increased amygdala activation related to the processing of negative emotions in S allele carriers. In addition, some studies report $\mathrm{S}$ allele-associated elevated ACC activity and reduced functional coupling between amygdala and MPFC/ACC.

Lesch and colleagues demonstrated in vitro that the 5-HTTLPR polymorphism is associated with changes in 5-HTT expression, coming along with a two-fold reduced 5-HT-reuptake in S allele carriers as compared to homozygous L allele carriers (Lesch et al., 1996). Heinz and colleagues were the first to show in vivo alterations in 5-HTT binding due to 5-HTTLPR (Heinz et al., 2000). Using $\beta$-CIT SPECT imaging, they detected reduced 5 -HTT binding levels in the dorsal raphe nuclei of human $S$ allele carriers. Given the fact that the serotonin transporter is the main target of antidepressant serotonin-reuptake inhibition (Chang et al., 1996; Zhou et al., 2009), the difference between the amygdala activation in $\mathrm{S}$ allele carriers and antidepressive medicated subjects on the one hand (both facilitate synaptic serotonin elevation), and the pattern of reduced amygdala and PFC activation in response to ATD on the other hand does not appear conclusive immediately Trying to disentangle this observed phenomenon, looking at serotonergic effects on the development of the central nervous system (CNS) might provide an explanatory approach. Already Ansorge and colleagues have investigated the seeming paradox between 5-HTT-lacking mice exhibiting increased depressive and anxious behaviours and long-term SSRI treatments leading to a reduction of 5-HTT and decreased depression- and anxiety-related symptoms (Ansorge et al., 2004). Administering the SSRI fluoxetine to postnatal mice, Ansorge and colleagues induced a transient 5-HTT inhibition during early development of the animals. As a consequence, mice positive for 5-HTT treated with fluoxetin postnatally showed the same anxious and depressive behaviours such as 5HTT-deficient conspecifics. The authors draw the conclusion that gene polymorphisms reducing 5-HTT expression might exert their effects in early stages of CNS development by changing the maturation of emotion-modulatory neural circuits. With this in mind, several molecular 5-HTTLPR-associated effects on serotonin receptor regulation, especially regarding $5-\mathrm{HT}_{1 \mathrm{~A}}, 5-\mathrm{HT}_{2 \mathrm{C}}$, and $5-\mathrm{HT}_{2 \mathrm{~A}}$ receptors, may provide an explanatory approach for these seemingly paradoxical neuroimaging fndings (for an excellent overview on serotonergic mechanisms related to cerebral threat reactivity, see the reviews by Canli and Lesch, 2007; Hariri and Holmes, 2006; Fisher and Hariri, 2013).

In animal models, mice deficient for the serotonin transporter revealed a significant reduction in $5-\mathrm{HT}_{1 \mathrm{~A}}$ receptor expression (Holmes et al., 2003). Additionally, 5-HTT knockout (KO) mice showed a $5-\mathrm{HT}_{1 \mathrm{~A}}$ autoreceptor downregulation in dorsal raphe neurons (Gobbi et al., 2001; Kim et al., 2005). Thus, a genetically driven absence of the serotonin transporter has been associated with a reduced expression or downregulation of $5-\mathrm{HT}_{1 \mathrm{~A}}$ autoreceptors leading to diminished serotonergic autoregulation in raphe nuclei. For humans, Fisher et al. (2006) could show an inverse relationship between $5-\mathrm{HT}_{1 \mathrm{~A}}$ autoreceptor density in dorsal raphe nuclei and threat-related amygdala activation using a combined fMRI-PET approach. The authors hypothesized a 5- $\mathrm{HT}_{1 \mathrm{~A}}$ receptor-mediated loss of negative feedback regulation, leading to disinhibited arousal of the amygdala. Accordingly, using PET, David et al. (2005) observed decreased 5- $\mathrm{HT}_{1 \mathrm{~A}}$ binding potentials in several brain areas, including raphe nuclei and ACC, associated with 5-HTTLPR S allele load. (Since contradicting findings were discussed (Lee et al., 2005), this has to be regarded cautiously.) In sum, attenuated $5-\mathrm{HT}_{1 \mathrm{~A}}$ receptor density in raphe nuclei has been associated with human amygdala response to threat. Furthermore, decreased $5-\mathrm{HT}_{1 \mathrm{~A}}$ receptor binding in raphe nuclei and ACC has been related to the $\mathrm{S}$ allele of the 5-HTTLPR polymorphism. Another 5-HT receptor of interest for a deeper understanding of 5-HTTLPR-associated corticolimbic activation is the $5-\mathrm{HT}_{2} \mathrm{C}$ receptor.

Regarding a potential role in emotion processing for the 5$\mathrm{HT}_{2 \mathrm{C}}$ receptor, microinjecting $5-\mathrm{HT}_{2 \mathrm{C}}$ agonists in the amygdala of rats induced a fear-related behavioural response (Campbell and Merchant, 2003; De Mello Cruz et al., 2005). An increase in 5$\mathrm{HT}_{2 \mathrm{C}}$ receptor availability, while $5-\mathrm{HT}_{1 \mathrm{~A}}$ receptor is downregulated, has previously been discussed as facilitating an amygdala state of hyperexcitability (Hariri and Holmes, 2006). Taken together, 5$\mathrm{HT}_{2 \mathrm{C}}$ receptor stimulation has been linked to fear-related behaviour in animals. Additionally, an upregulation of $5-\mathrm{HT}_{2 \mathrm{C}}$ receptor in association with a downregulation of $5-\mathrm{HT}_{1 \mathrm{~A}}$ receptor has been suggested to promote heightened amygdala activation. Besides $5-\mathrm{HT}_{1 \mathrm{~A}}$ and $5-\mathrm{HT}_{2 \mathrm{C}}$ receptors, one more 5 - $\mathrm{HT}$ receptor increasingly came into focus of emotion processing research, the $5-\mathrm{HT}_{2 \mathrm{~A}}$ receptor.

In humans, recent neuroimaging studies have reported $5-\mathrm{HT}_{2 \mathrm{~A}^{-}}$ and $5-\mathrm{HT}_{1 \mathrm{~A}}$-associated alterations related to aversive emotion regulation. In a combined PET-fMRI study on healthy volunteers, Fisher et al. (2009) reported an inverse correlation between 5- $\mathrm{HT}_{2 \mathrm{~A}}$ receptor density in the MPFC and threat-associated amygdala activation, using the face matching paradigm (threat-related: fearful/angry faces) by Hariri et al. (2002). Furthermore, they found 5- $\mathrm{HT}_{2 \mathrm{~A}}$ density in the MPFC correlating with the magnitude of amygdala-MPFC functional connectivity (Fisher et al., 2009). In a further investigation, Fisher and colleagues revealed that the aforementioned inverse relationship between medial prefrontal $5-\mathrm{HT}_{2 \mathrm{~A}}$ receptor density and amygdala signaling was significantly moderated by low 5- $\mathrm{HT}_{1 \mathrm{~A}}$ receptor binding in the MPFC (Fisher et al., 2011). Additionally, in an fMRI study by Hornboll et al. (2013), the 5-HT2A receptor antagonist ketanserin was associated with an increase in medial OFC activation and medial OFC-left amygdala functional coupling during the processing of fearful faces in a gender recognition task. To sum up, these investigations could reveal an increased amygdala excitation correlating with diminished $5-\mathrm{HT}_{2 \mathrm{~A}}$ availability in the MPFC associated with lowered $5-\mathrm{HT}_{1 \mathrm{~A}}$ receptor function in the MPFC during threat-related emotional face processing. Considering threat-related amygdala activation increase in $\mathrm{S}$ allele carriers associated with $5-\mathrm{HT}_{1 \mathrm{~A}}$ and $5-\mathrm{HT}_{2 \mathrm{~A}}$ receptor hypofunctionality, the observed medial prefrontal $5-\mathrm{HT}_{2 \mathrm{~A}}$ receptor density-related amygdala-MPFC functional connectivity effect might serve as an explanatory approach for the $\mathrm{S}$ allele-driven decreased corticolimbic functional coupling found in the 5-HTTLPR neuroimaging studies (for an overview of 5-HTTLPR-associated 5-HT receptor alterations, see Fig. 3). All in all, S allele carriers appear to have a disinhibited sertonergic modulation of amygdala activity during facial emotion processing associated with altered serotonin receptor relationships in raphe nuclei and medial prefrontal or anterior cingulate cortex. These considerations might provide one possible answer narrowing the question why the threat-related neural activation patterns associated with the drug-induced serotonin elevation vary from the 5-HTTLPR polymorphism effect.

\section{Conclusions, limitations, and future directions}

This review explored the neuroimaging findings on the processing of emotional facial expressions, taking account of serotonergic 


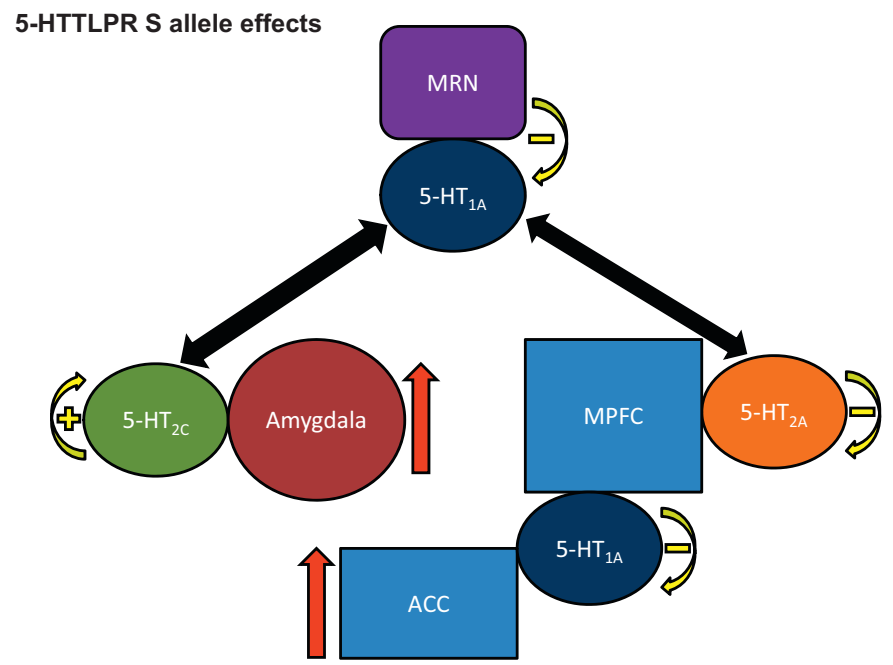

Fig. 3. 5-HTTLPR model (S allele-promoted synaptic serotonin increase): S alleleassociated availability of $5-\mathrm{HT}_{1 \mathrm{~A}}, 5-\mathrm{HT}_{2 \mathrm{C}}$, and $5-\mathrm{HT}_{2 \mathrm{~A}}$ receptors (curved arrow up/down =up-/downregulation), reciprocal receptor relationships (black double arrow), and brain region activation increases (red arrow). $\mathrm{MRN}=$ midbrain raphe nuclei, $\mathrm{MPFC}=$ medial prefrontal cortex, $\mathrm{ACC}=$ anterior cingulate cortex.

modulation. We aimed to examine the influence of 5-HTTLPR, serotonin-reuptake inhibiting antidepressant drugs and ATD on neural circuit activation (encompassing amygdala, OFC, ACC, and MPFC) associated with the processing of emotional facial expressions. We have reviewed studies that demonstrated serotonin effects on activation of brain areas for social processing. Nevertheless, since our review considered only studies investigating the processing of emotional faces, future research needs to verify if our model can also be applied to other social-cognitive functions, such as theory of mind, or emotion processing in general. Furthermore, for future investigations several other aspects seem worth to be considered and some limitations have to be mentioned.

Regarding candidate genes, several other genetic regions besides 5-HTTLPR have been associated with emotion processing or social cognition. Among them are polymorphisms concerning catechol-o-methyltransferase (COMT) (Egan et al., 2001; Heinz and Smolka, 2006; Mier et al., 2010a), monoamine oxidase-A (MAOA) (Buckholtz and Meyer-Lindenberg, 2008; Meyer-Lindenberg et al., 2006), or oxytocin (Bethlehem et al., 2013; Sauer et al., 2012; Skuse and Gallagher, 2011; Tost et al., 2010). Additionally, neuroimaging findings on 5-HT receptor genes in emotion processing appear as another road for further investigation (Iidaka et al., 2005; Kilpatrick et al., 2011).

Besides studies on different single gene effects, more sophisticated imaging genetics analysis techniques, taking biologic interactions of several genes (gene x gene interaction, "epistasis") on brain activation into account, have been developed (Bigos and Weinberger, 2010). For example, Pezawas and colleagues found an epistatic effect of 5-HTTLPR and the neurotrophin brain-derived neurotrophic factor (BDNF) on corticolimbic volume alterations (Pezawas et al., 2008). Several gene $\mathrm{x}$ gene interactions on neural activation during emotion processing have already beeen reported (e.g., Naudts et al., 2012; Outhred et al., 2012; Wang et al., 2012). Furthermore, the development of polygenic risk models is suggested to be a promising field within the next wave of imaging genetics (Birnbaum and Weinberger, 2013), leading to a more profound understanding and more realistic and complex genetical models of brain function.

Moreover, it should be mentioned that there are general concerns regarding the endophenotype concept which is the theoretical basis for imaging genetics studies (Bigos and Hariri, 2007;
Gottesmann and Gold, 2003; Hariri et al., 2006; Meyer-Lindenberg and Weinberger, 2006). Specifically, some potential risks for data interpretation are under discussion (Flint and Munafò, 2007; Kendler and Neale, 2010; Walters and Owen, 2007) and have to be kept in mind when assessing the results of studies presented in our review. Walters and Owen emphasize four possible schematic relationships between genes, endophenotypes, and psychiatric disease phenotypes which should be taken into account: (1) The endophenotype is a consequence of disease symptoms or state, (2) the endophenotype is an epiphenomenon, (3) different genes are associated with endophenotypes and disease, and (4) the endophenotype arises from non-genetic factors (Walters and Owen, 2007). For a further discussion of limitations of this endophenotype approach, see the articles by Flint and Munafò (2007), Kendler and Neale (2010), and Walters and Owen (2007). Indpendent of the validity of the endophenotype concept, there are further issues with 5-HTTPLR imaging genetics studies (Bastiaansen et al., 2014; Munafò et al., 2008; Murphy et al., 2013). In 2008, Munafò and colleagues published a meta-analysis on 5-HTTLPR imaging genetics studies on amygdala activation during emotion processing (Munafò et al., 2008). They found the 5-HTTLPR polymorphism accounting for up to $10 \%$ of phenotypic variance, supporting the association of the polymorphism and the phenotype. Nevertheless, they concluded that most studies published lack in statistical power, mainly due to too small sample sizes. They recommended that samples should at least encompass 70 participants, assuming equal numbers of each genotype. Furthermore, they concluded that studies showing negative results and therefore are less likely to be published lead to a publication bias, distorting estimations of the likely magnitude of effects of associations. In another meta-analysis, Murphy and colleagues reported a small but significant effect of the S allele on amygdala activation (Murphy et al., 2013). They also pointed to a majority of underpowered studies with significant findings, mainly because of too small sample sizes as main source of study outcome variations. Furthermore, the authors underline the danger of not publishing negative results, promoting a publication bias. Interestingly, their meta-analysis was stratified for several factors of between-study heterogeneity, e.g., imaging methods used, task designs, contrasts used within the subtraction methods etc., not finding any significant moderating influence of study design characteristics. Bastiaansen and colleagues reported metaanalytic results (Bastiaansen et al., 2014), including unpublished studies added to the body of studies analyzed by Murphy et al. (2013). They found previously significant effect size no longer significant, suggesting the genotype-phenotype association smaller than previously assumed. In conclusion, the authors emphasized the need for null results publications to fight publication bias. All in all, further studies with increased sample sizes and a greater acceptance of null results publications are needed. For a greater overview of the discussion, see the publications by Bastiaansen et al. (2014), Munafò et al. (2008), and Murphy et al. (2013). Regarding sample sizes of the 5-HTTLPR studies reviewed in here, only 6 studies included at least 70 participants (Bastiaansen et al., 2014; Domschke et al., 2012; Fisher et al., 2015; Hariri et al., 2005; Pezawas et al., 2005; Surguladze et al., 2012) as recommended by Munafò et al. (2008). Two more studies had almost 70 participants (Von dem Hagen et al., 2011, $\mathrm{n}=68$; Walsh et al., 2012, $n=67$ ). Furthermore, because of inhomogenous allelic distribution, in some studies the building of genotype groups (e.g., S vs. L/L) was required for comparison purposes. Only 9 of the 25 studies reported groups quite equal in size due to genotype grouping (Hariri et al., 2002; Fisher et al., 2014; Lonsdorf et al., 2011 O'Nions et al., 2011; Volman et al., 2013; Von dem Hagen et al., 2011; Walsh et al., 2012; Waring et al., 2014; Wiggins et al., 2014). Furthermore, the triallelic approach in analyzing the 5-HTTLPR genotype has only been considered in 10 of the reviewed studies (Costafreda et al., 2013; 
Dannlowski et al., 2010, 2008; Domschke et al., 2012; Fisher et al., 2015, 2014; O'Nions et al., 2011; Surguladze et al., 2012; Thomason et al., 2010; Wiggins et al., 2014), promoting variation in sensitivity for detecting differences in cerebral activation (Bastiaansen et al., 2014). To summarize, inconsistent neuroimaging results of the reviewed studies might be related to issues with sample size or allele distribution. Further research on these aspects is required.

Regarding pharmacological fMRI, there are some limitations concerning the interpretation of measured neuronal activation. A repeatedly discussed issue is the vasoactive impact of administered compounds and the changes in the vasoactive coupling or blood oxygen level-dependency (BOLD) measured by fMRI (Honey and Bullmore, 2004; Wise and Tracey, 2006). Since the vascular signaling system encompasses multiple vasoactive agents (e.g., potassium, neurotransmitters, neuropeptides, or nitric oxide) (Iadecola, 2004), which are thought to be pharmacologically modulated and to play a role in the increase of cerebral blood flow, the complexity of interaction between the pharmacological agent and vascular effects has to be taken into account, while interpreting the neuronal activation (Honey and Bullmore, 2004; Wise and Tracey, 2006). Another issue is the interpretation of drugrelated brain activation changes without behavioural alterations, which can on the one hand nihilistically be seen as epiphenomenal, or on the other hand as the result of compensatory cerebrofunctional adaptions (Honey and Bullmore, 2004). For a deeper overview of the discussion, see the excellent reviews by Honey and Bullmore (2004) and Wise and Tracey (2006). In addition, a recent meta-analysis of Ma (2015) on neuroimaging studies, investigating antidepressants effects during emotion processing, pointed to potential factors causing inconsistent results between studies. The analyses revealed different brain activation in response to antidepressant pharmacologic modulation dependent on single or repeated administration. The studies reviewed in here differed in their dosage design, encompassing administration of antidpressants as single-dose (Anderson et al., 2007; Bigos et al., 2008; Del-Ben et al., 2005; Klomp et al., 2013; Ma et al., 2015; Murphy et al., 2009; Terburg et al., 2013), administration for 7 days (Di Simplicio et al., 2014; Harmer et al., 2006), for 7-10 days (Norbury et al., 2009), for 10 days (Windischberger et al., 2010), for 14 days (Van Marle et al., 2011), and for 21 days (Arce et al., 2008). Furthermore, inconsistencies in antidepressants effects might be related to different dosages or ways of administration (oral vs. intravenous) (Ma, 2015). The studies differed not only in administration frequencies, but also in citalopram dosages given to the participants, such as 7,5 mg (Anderson et al., 2007; Del-Ben et al., 2005), $20 \mathrm{mg}$ (Di Simplicio et al., 2014; Harmer et al., 2006; Klomp et al., 2013; Murphy et al., 2009; Norbury et al., 2009; Windischberger et al., 2010; Bigos et al., 2008), or $30 \mathrm{mg}$ (Ma et al., 2015). The three other studies used 5 and $10 \mathrm{mg}$ of escitalopram (Arce et al., 2008), $25 \mathrm{mg}$ of Zembrin (Terburg et al., 2013), or $60 \mathrm{mg}$ of duloxetine (Van Marle et al., 2011). Regarding the administration method, 10 studies used oral drug administration (Arce et al., 2008; Di Simplicio et al., 2014; Harmer et al., 2006; Klomp et al., 2013; Ma et al., 2015; Murphy et al., 2009; Norbury et al., 2009; Terburg et al., 2013; Van Marle et al., 2011; Windischberger et al., 2010), wereas in 3 studies participants took the antidepressant intravenously (Anderson et al., 2007; Bigos et al., 2008; Del-Ben et al., 2005). Additionally, other factors are thought to modulate the antidepressants effects, such as gender or genes (Ma, 2015). The studies reviewed in here showed differences in gender compositions of the samples, with only males (Anderson et al., 2007; Del-Ben et al., 2005; Di Simplicio et al., 2014; Ma et al., 2015), only females (Arce et al., 2008; Bigos et al., 2008; Klomp et al., 2013), mostly males (Harmer et al., 2006; Windischberger et al., 2010), or balanced for sex (Murphy et al., 2009; Terburg et al., 2013; Van Marle et al., 2011). Regarding genetic effects, only the study by Ma et al. (2015) reported 5-HTTLPR polymorphism effects (see above). Thus, in addition to general critics on pharmacological challenge studies, there are several factors potentially promoting inconsistent results and complicating comparability between studies, emphasizing the need for further investigations.

Regarding serotonergic antidepressant drug effects, the effect of chronic SSRI treatment on emotion processing should be studied more extensively to investigate the effect of 5-HT receptor desensitization (Blier et al., 1990; Celada et al., 2004; El Mansari et al., 2005; Hervás et al., 2001). Furthermore, 5-HTT polymorphism effects on the efficacy of antidepressants have been reported (Karlović and Karlović, 2013; Porcelli et al., 2012; Serretti et al., 2007; Smits et al., 2004). However, only the study by Ma and colleagues investigated this relationship refering to emotional face processing (Ma et al., 2015). Further studies might be of intertest to investigate the impact of the interaction of genetics and drug therapy on facial emotion processing.

Although ATD is currently regarded as one of the most established methods to investigate the serotonergic involvement in the neurobiology of affective disorders, the extent to which ATD alters serotonin directly or indirectly and the underlying neurobiological mechanisms are still unclear (Van Donkelaar et al., 2011; Young, 2013). One critical aspect regarding the extent of the impact of ATD on cerebral serotonin levels is that it cannot be measured directly in humans, but is estimated based on peripheral tryptophan levels (Van Donkelaar et al., 2011). Van Donkelaar and colleagues emphasize that often for analyses needed total and free tryptophan levels as well as amino acids competing with tryptophan, like methionine and threonine, are not integrated in estimations, promoting distorted results (Van Donkelaar et al., 2011). Other potential confounding factors are e.g., influences of ATD on nitric oxide synthase, cerebrovascular dynamics, and stress, which furthermore are thought to have an impact on serotonin levels, complicating the interpretation of ATD effects on serotonin (Van Donkelaar et al., 2011; Young, 2013). Young suggests that being in an fMRI scanner as compared to a quiet room might already change the ATD effect on serotonin release due to a state of greater arousal (Young, 2013). For an overview of the discussion, see the excellent reviews by Crockett et al. (2012), Van Donkelaar et al. (2011), and Young (2013). Further, in terms of inconsistencies in results of ATD neuroimaging studies on emotion processing, Evers et al. (2010) underlined small sample sizes, differences in tasks used, and gender of the participants as potential confounding influences. Regarding the sample sizes of the studies reviewed in here, it has to be mentioned that the numbers of participants is relatively small, with only 1 study with over 30 participants (Kroes et al., 2014; $n=32$ ). Furthermore, regarding the tasks used, the 8 included studies used 4 different tasks (see above). Focusing on the gender of the participants, the studies reviewed in here differed in the composition, with groups of only males (Cools et al., 2005; Williams et al., 2007), only females (Kroes et al., 2014; Van der Veen et al., 2007), mostly males (FusarPoli et al., 2007; Grady et al., 2013; Robinson et al., 2013), or mostly females (Passamonti et al., 2012). Nevertheless, the ATD effect on amygdala activation is quite consistent, emphasizing the importance of this observed effect.

Since differences in 5-HT receptor regulation dependent on the period of tryptophan alteration have been reported (Cahir et al., 2007), further studies need to investigate differences between effects of acute and chronic tryptophan depletion on serotonin. Additionally, ATD has been proposed to influence not only serotonin, but also proteins likely relevant for brain function, e.g., BDNF (Van Donkelaar et al., 2011). Since BDNF has been associated with alterations in cognitive and emotional processing (Domingos da Silveira da Luz et al., 2013; Lu et al., 2014; Scharinger et al., 2010), studying an BDNF-allelic effect on corticolimbic signaling after tryptophan modulation in response to facial emotion processing 
could be a promising path to a deeper understanding of underlying neurobiological mechanisms of social-cognitive functioning derived from pharmacogenetic effects.

Even though many of the reviewed studies focused on amygdala and ACC activation, a limitation of this review might be the restriction to specific brain areas. Since different other regions previously associated with serotonergic modulation, such as insula (Klumpp et al., 2014), and striatum (Balcioglu and Wurtman, 2000 Navailles and De Deurwaerdère, 2011; Zhou et al., 2005), are suggested to play a role in emotion processing, an extended set of brain areas seems necessary for a comprehensive neurobiological understanding. Additionally, the aspect of hemisphere-dependent area activation as regarded elsewhere (Hardee et al., 2008; Nakamura et al., 2014) should be taken into consideration.

Another important factor which makes the comparability of studies increasingly complicated is the heterogeneity of fMRI paradigms. On the one hand, many of the studies on emotional face processing reviewed used different tasks associated with different activation patterns; on the other hand, some tasks do not clearly allow to differentiate between cognitive or affective brain functions tested (e.g., emotion processing vs. word processing, working memory, or conflict monitoring). To enhance our understanding of genetic effects on brain activation, future tasks should be more homogenous and preferentially focused on single brain functions. Such an attempt to synchronize modern psychiatric research can be found in the Research Domain Criterea (RDoC), as recommended by the National Institute of Mental Health (NIMH) (Cuthbert 2015; Cuthbert and Insel, 2013; Cuthbert and Kozak, 2013; Insel et al., 2010; Insel, 2014)

In 2010, Thomas Insel and colleagues from the NIMH published a commentary in the American Journal of Psychiatry, introducing a new approach for classifying mental illness for research purposes, the RDoC (Insel et al., 2010). The current psychiatric diagnostic systems, as the Diagnostic and Statistical Manual of Mental Disorders (DSM; American Psychiatric Association, 2013) and the mental and behavioural disorders section of the International Classification of Diseases (World Health Organization, 1992), define diagnoses in terms of nosological categories based on clusters of symptoms, regardless of neurobiological underpinnings of mental illnesses (Cuthbert, 2015; Cuthbert and Insel, 2013; Cuthbert and Kozak, 2013; Insel et al., 2010; Insel, 2014). The $\mathrm{RDoC}$ project aims for a taxonomic system for research purposes, taking neurobiological evidence into account and resting on the assumptions that mental illnesses are the results of dysfunctional brain circuits which can be neuroscientifically identified (e.g., with functional neuroimaging, electrophysiology etc.), and ideally lead to the development of biosignatures ("constructs") presumed to underlie core symptoms of mental disorders, indicating a certain clinical management (Casey et al., 2014; Insel et al., 2010). The innovative dimensional approach of RDoC divides the system into five research "domains": Negative valence domain, positive valence systems, cognitive systems, systems for social processes, and arousal/modulatory systems (Cuthbert, 2014; Cuthbert and Insel, 2013). Each of these domains consists of several "constructs" and "subconstructs" (Cuthbert, 2014; Cuthbert and Insel, 2013).

Regarding the placement within the RDoC system of the neural processing of emotional facial expression and the impact of genetic polymorphisms or pharmacological challenge, as reviewed in here, the NIMH assigns the domain "social processes", the construct "social communication", and the subconstruct "reception of facial communication" to paradigms testing emotional facial expressions (see http://www.nimh.nih.gov/research-priorities/ rdoc/rdoc-constructs.shtml). Following the RDoC rationale of the implementation of empirical neuroscientific evidence (see http://www.nimh.nih.gov/research-priorities/rdoc), our model combines different levels of analysis, e.g., genetics (5-HTTLPR), molecules (serotonin, pharmacologic drugs, tryptophan, 5-HTT, 5-HT receptors), neural circuits (cortico-limbic), physiology (brain activation as measured by fMRI), and behaviour (identification of emotion), demonstrating an approach in line with the RDoC principles. What is missing in the current review is providing the dimensional approach recommended in the RDoC. For example, Dannlowski and colleagues showed an increase in amygdala activity during passively viewing masked emotional faces in $\mathrm{S}$ and $\mathrm{L}_{\mathrm{G}}$ allele carriers as compared to $\mathrm{L}_{\mathrm{A}} / \mathrm{L}_{\mathrm{A}}$ homozygotes in a sample consisting of healthy controls and patients with major depression (Dannlowski et al., 2008). This effect remained significant in the patient group alone, but not in the healthy control group. In the study by Costafreda and colleagues, elevated amygdala activation during a gender recognition faces task in $\mathrm{S}$ as compared to L allele carriers, as well as in $\mathrm{S}_{\mathrm{A}}, \mathrm{S}_{\mathrm{G}}$, and $\mathrm{L}_{\mathrm{G}}$ allele carriers as compared to $\mathrm{L}_{\mathrm{A}} / \mathrm{L}_{\mathrm{A}}$ allele homozygotes was reported (Costafreda et al., 2013). The sample consisted of patients with recurrent depression and healthy controls. The effect of greater amygdala response was more intense in the patient group as compared to the healthy controls. These results suggest that the impact of the $S$ allele might even be stronger in patient groups. However, an analysis of how the described interplay of different serotonin receptors with the serotonin transporter applies to the results from patient studies is needed.

Finally, despite limitations, we found empirical evidence for cerebral activation patterns related to 5-HTTLPR allele-associated alterations in serotonergic neurotransmission. The reviewed 5HTTLPR studies indicate increased amygdala activation, an elevated ACC activation and reduced functional coupling between amygdala and MPFC/ACC related to the processing of negative emotions in $S$ allele carriers (see Fig. 1). For comparison, we regarded these results in relation to pharmacological challenge neuroimaging findings from antidepressants and ATD studies. Antidepressants neuroimaging studies reviewed here suggest a hypoactivation of amygdala, frontal and cingulate cortex under medication during facial emotion processing (see Fig. 1). The reviewed ATD publications indicate an elevation in amygdala and prefrontal/cingulate responsivity and functional coupling between these corticolimbic areas to emotional faces after ATD (see Fig. 1). Thus, contrary to our expectations, these studies revealed activation patterns which were not immediately explained by solely regarding the influences of the investigated genes, or the drugs on neurotransmitter concentrations. Trying to bring these different neuroimaging findings into line with theories on neurotransmitter biology, we discussed these imaging findings in the light of recent neurobiological evidence, especially on serotonin receptor relationships. Based on that, we propose a neurobiological model, suggesting that 5HTTLPR genotype-, antidepressants- and ATD-induced alterations in 5- $\mathrm{HT}_{1 \mathrm{~A}}, 5-\mathrm{HT}_{2 \mathrm{~A}}$, and $5-\mathrm{HT}_{2 \mathrm{C}}$ receptor activation, distribution, and binding behaviour might play a critical role in corticolimbic activation during emotional face processing. Within this model, studies on antidepressants suggest an increase in extracellular serotonin concentration in midbrain raphe nuclei. This serotonin elevation has been thought to activate inhibitory $5-\mathrm{HT}_{1 \mathrm{~A}}$ autoreceptors, leading to a diminished serotonergic corticolimbic firing (see Fig. 2). As opposed to this, ATD has been observed to lower plasma serotonin concentrations, facilitating a reduction in $5-\mathrm{HT}_{1 \mathrm{~A}}$ autoreceptor binding in raphe nuclei. Furthermore, this promotes an attenuated feedback inhibition of corticolimbic activation, what might explain the heightened corticolimbic responsivity during facial emotion processing (see Fig. 2). Regarding the 5-HTTLPR effects, within our model, (5-HTTLPR S allele-associated) 5-HTT reduction facilitates a downregulation of 5- $\mathrm{HT}_{1 \mathrm{~A}}$ receptors in raphe nuclei which has been associated with an increased amygdala response to threat. Additionally, a decreased 5- $\mathrm{HT}_{1 \mathrm{~A}}$ receptor binding in raphe nuclei and ACC has been related to the $S$ allele of the 5-HTTLPR polymorphism. 
Further, linked to a downregulation of $5-\mathrm{HT}_{1 \mathrm{~A}}$ receptors, an upregulation of $5-\mathrm{HT}_{2 \mathrm{C}}$ receptors has been described. $5-\mathrm{HT}_{2 \mathrm{C}}$ receptor stimulation in amygdala has been linked to fear-related behaviours. In sum, these $5-\mathrm{HT}_{1 \mathrm{~A}}$ receptor and $5-\mathrm{HT}_{2} \mathrm{C}$ receptor alterations have been thought to promote heightened amygdala response to emotional cues. Furthermore, associated with a lowered medial prefrontal $5-\mathrm{HT}_{1 \mathrm{~A}}$ receptor function, an increased amygdala excitation has been found correlating with diminished medial prefrontal 5- $\mathrm{HT}_{2 \mathrm{~A}}$ receptor availability during threat-related emotional face processing. We think this interplay of serotonin receptors with serotonin transporter variations serves as an explanatory approach for the $\mathrm{S}$ allele-driven decreased corticolimbic functional coupling found in the 5-HTTLPR neuroimaging studies (For an overview of the model, see Fig. 3).

All in all, we believe our review provides evidence of serotonergically driven functional corticolimbic circuit architecture during social-cognitive functioning and a contribution to a deeper understanding of its neurobiological underpinnings, hopefully facilitating further steps towards a personalized medical treatment.

\section{Conflict of interest}

The authors declare no conflict of interest.

\section{Acknowledgement}

We thank Stephanie N.L. Schmidt for helpful comments on the manuscript.

\section{References}

Abi-Saab, W.M., Bubser, M., Roth, R.H., Deutch, A.Y., 1999. 5-HT2 receptor regulation of extracellular GABA levels in the prefrontal cortex. Neuropsychopharmacology 20, 92-96, http://dx.doi.org/10.1016/S0893133X(98)00046-3.

Adell, A., Artigas, F., 1991. Differential effects of clomipramine given locally or systemically on extracellular 5-hydroxytryptamine in raphe nuclei and frontal cortex. An in vivo brain microdialysis study. Naunyn Schmiedebergs Arch. Pharmacol. 343, 237-244.

Adolphs, R., Tranel, D., Damasio, H., Damasio, A.R., 1995. Fear and the human amygdala. J. Neurosci. 15, 5879-5891.

Adolphs, R., Tranel, D., Hamann, S., Young, A.W., Calder, A.J., Phelps, E.A., Anderson, A., Lee, G.P., Damasio, A.R., 1999. Recognition of facial emotion in nine individuals with bilateral amygdala damage. Neuropsychologia 37, 1111-1117.

Adolphs, R., 2001. The neurobiology of social cognition. Curr. Opin. Neurobiol. 11, 231-239.

Adolphs, R., 2002a. Recognizing emotion from facial expressions: psychological and neurological mechanisms. Behav. Cogn. Neurosci. Rev. 1, 21-62.

Adolphs, R., 2002b. Neural systems for recognizing emotion. Curr. Opin. Neurobiol. $12,169-177$.

Adolphs, R., 2003. Cognitive neuroscience of human social behaviour. Nat. Rev. Neurosci. 4, 165-178, http://dx.doi.org/10.1038/nrn1056.

Aghajanian, G.K., Marek, G.J., 1999. Serotonin, via 5-HT2A receptors, increases EPSCs in layer $\mathrm{V}$ pyramidal cells of prefrontal cortex by an asynchronous mode of glutamate release. Brain Res. 825, 161-171.

Akimova, E., Lanzenberger, R., Kasper, S., 2009. The serotonin-1A receptor in anxiety disorders. Biol. Psychiatry 66, 627-635, http://dx.doi.org/10.1016/j. biopsych.2009.03.012.

Aloyo, V.J., Berg, K.A., Clarke, W.P., Spampinato, U., Harvey, J.A., 2010. Inverse agonism at serotonin and cannabinoid receptors. Prog. Mol. Biol. Transl. Sci. 91 1-40, http://dx.doi.org/10.1016/S1877-1173(10)91001-6.

Altieri, S.C., Garcia-Garcia, A.L., Leonardo, E.D., Andrews, A.M., 2013. Rethinking 5-HT1A receptors: emerging modes of inhibitory feedback of relevance to emotion-related behavior. ACS Chem. Neurosci. 4, 72-83, http://dx.doi.org/10. $1021 / \operatorname{cn} 3002174$

Amaral, D.G., Price, J.L., 1984. Amygdalo-cortical projections in the monkey (Macaca fascicularis). J. Comp. Neurol. 230, 465-496, http://dx.doi.org/10. $1002 /$ cne.902300402.

Amargós-Bosch, M., Bortolozzi, A., Puig, M.V., Serrats, J., Adell, A., Celada, P., Toth, M., Mengod, G., Artigas, F., 2004. Co-expression and in vivo interaction of serotonin1 A and serotonin $2 \mathrm{~A}$ receptors in pyramidal neurons of prefrontal cortex. Cereb. Cortex 14, 281-299.

American Psychiatric Association, 2013. Diagnostic and Statistical Manual of Mental Disorders, 5th ed. American Psychiatric Publishing, Arlington.

Anderson, I.M., Del-Ben, C.M., Mckie, S., Richardson, P., Williams, S.R., Elliott, R., Deakin, J.F.W., 2007. Citalopram modulation of neuronal responses to aversive face emotions: a functional MRI study. Neuroreport 18, 1351-1355, http://dx. doi.org/10.1097/WNR.0b013e3282742115.

Andrade, R., Haj-Dahmane, S., 2013. Serotonin neuron diversity in the dorsal raphe. ACS Chem. Neurosci. 4, 22-25, http://dx.doi.org/10.1021/cn300224n.

Ansorge, M.S., Zhou, M., Lira, A., Hen, R., Gingrich, J.A., 2004. Early-life blockade of the 5-HT transporter alters emotional behavior in adult mice. Science 306, 879-881, http://dx.doi.org/10.1126/science.1101678.

Arce, E., Simmons, A.N., Lovero, K.L., Stein, M.B., Paulus, M.P., 2008. Escitalopram effects on insula and amygdala BOLD activation during emotional processing. Psychopharmacology (Berl.) 196, 661-672, http://dx.doi.org/10.1007/s00213007-1004-8.

Artigas, F., Romero, L., de Montigny, C., Blier, P., 1996. Acceleration of the effect of selected antidepressant drugs in major depression by 5-HT1 A antagonists. Trends Neurosci. 19, 378-383, http://dx.doi.org/10.1016/S01662236(96)10037-0.

Artigas, F., 2013. Serotonin receptors involved in antidepressant effects. Pharmacol Ther. 137, 119-131, http://dx.doi.org/10.1016/j.pharmthera.2012.09.006.

Aznar, S., Klein, A.B., 2013. Regulating prefrontal cortex activation: an emerging role for the 5-HT2A serotonin receptor in the modulation of emotion-based actions? Mol. Neurobiol. 48, 841-853, http://dx.doi.org/10.1007/s12035-0138472-0

Balcioglu, A., Wurtman, R.J., 2000. Striatal serotonin receptors and dopamine release. J. Neurochem. 75, 886.

Barbas, H., De Olmos, J., 1990. Projections from the amygdala to basoventral and mediodorsal prefrontal regions in the rhesus monkey. J. Comp. Neurol. 300, 549-571, http://dx.doi.org/10.1002/cne.903000409.

Barnes, N.M., Sharp, T., 1999. A review of central 5-HT receptors and their function. Neuropharmacology 38, 1083-1152.

Barnes, J.J.M., Dean, A.J., Nandam, L.S., O'Connell, R.G., Bellgrove, M.A., 2011. The molecular genetics of executive function: role of monoamine system genes. Biol. Psychiatry 69, e127-143, http://dx.doi.org/10.1016/j.biopsych.2010.12. 040.

Bastiaansen, J.A., Servaas, M.N., Marsman, J.B.C., Ormel, J., Nolte, I.M., Riese, H., Aleman, A., 2014. Filling the gap: relationship between the serotonin-transporter-linked polymorphic region and amygdala activation. Psychol. Sci. 25, 2058-2066, http://dx.doi.org/10.1177/0956797614548877.

Battaglia, M., Zanoni, A., Taddei, M., Giorda, R., Bertoletti, E., Lampis, V., Scaini, S., Cappa, S., Tettamanti, M., 2012. Cerebral responses to emotional expressions and the development of social anxiety disorder: a preliminary longitudinal study. Depression Anxiety 29, 54-61, http://dx.doi.org/10.1002/da.20896.

Bel, N., Artigas, F., 1992. Fluvoxamine preferentially increases extracellular 5-hydroxytryptamine in the raphe nuclei: an in vivo microdialysis study. Eur. J. Pharmacol. 229, 101-103.

Bel, N., Artigas, F., 1993. Chronic treatment with fluvoxamine increases extracellular serotonin in frontal cortex but not in raphe nuclei. Synapse 15 , 243-245, http://dx.doi.org/10.1002/syn.890150310.

Belsky, J., Jonassaint, C., Pluess, M., Stanton, M., Brummett, B., Williams, R., 2009. Vulnerability genes or plasticity genes? Mol. Psychiatry 14, 746-754, http://dx. doi.org/10.1038/mp.2009.44

Bertolino, A., Arciero, G., Rubino, V., Latorre, V., De Candia, M., Mazzola, V., Blasi, G., Caforio, G., Hariri, A., Kolachana, B., Nardini, M., Weinberger, D.R., Scarabino, T. 2005. Variation of human amygdala response during threatening stimuli as a function of 5'HTTLPR genotype and personality style. Biol. Psychiatry 57, 1517-1525, http://dx.doi.org/10.1016/j.biopsych.2005.02.031.

Bethlehem, R.A.I., van Honk, J., Auyeung, B., Baron-Cohen, S., 2013. Oxytocin, brain physiology, and functional connectivity: a review of intranasal oxytocin fMR studies. Psychoneuroendocrinology 38, 962-974, http://dx.doi.org/10.1016/j. psyneuen.2012.10.011.

Bevilacqua, L., Goldman, D., 2011. Genetics of emotion. Trends Cogn. Sci. 15, 401-408, http://dx.doi.org/10.1016/j.tics.2011.07.009.

Bigos, K.L., Hariri, A.R., 2007. Neuroimaging: technologies at the interface of genes, brain, and behavior. Neuroimaging Clin. N. Am. 17, 459-467, http://dx.doi.org/ 10.1016/j.nic.2007.09.005.

Bigos, K.L., Weinberger, D.R., 2010. Imaging genetics-days of future past. Neurolmage 53, 804-809, http://dx.doi.org/10.1016/j.neuroimage.2010.01. 035.

Bigos, K.L., Pollock, B.G., Aizenstein, H.J., Fisher, P.M., Bies, R.R., Hariri, A.R., 2008. Acute 5-HT reuptake blockade potentiates human amygdala reactivity. Neuropsychopharmacology 33, 3221-3225, http://dx.doi.org/10.1038/npp 2008.52.

Birnbaum, R., Weinberger, D.R., 2013. Functional neuroimaging and schizophrenia: a view towards effective connectivity modeling and polygenic risk. Dialogues Clin. Neurosci. 15, 279-289.

Blier, P., de Montigny, C., 1994. Current advances and trends in the treatment of depression. Trends Pharmacol. Sci. 15, 220-226.

Blier, P., de Montigny, C., Chaput, Y., 1990. A role for the serotonin system in the mechanism of action of antidepressant treatments: preclinical evidence. J. Clin. Psychiatry 51 (Suppl), 14-20 (discussion 21).

Blokland, A., Lieben, C., Deutz, N.E.P., 2002. Anxiogenic and depressive-like effects, but no cognitive deficits, after repeated moderate tryptophan depletion in the rat. J. Psychopharmacol. Oxf. Engl. 16, 39-49.

Bourke, C., Douglas, K., Porter, R., 2010. Processing of facial emotion expression in major depression: a review. Aust. N. Z. J. Psychiatry 44, 681-696, http://dx.doi. org/10.3109/00048674.2010.496359. 
Bragado-Jimenez, M.D., Taylor, P.J., 2012. Empathy, schizophrenia and violence: a systematic review. Schizophr. Res. 141, 83-90, http://dx.doi.org/10.1016/j. schres.2012.07.019.

Brothers, L., Ring, B., 1992. A neuroethological framework for the representation of minds. J. Cogn. Neurosci. 4, 107-118.

Brothers, L., 1990. The social brain: a project for integrating primate behavior and neurophysiology in a new domain. Concepts Neurosci. 1, 27-51.

Buckholtz, J.W., Meyer-Lindenberg, A., 2008. MAOA and the neurogenetic architecture of human aggression. Trends Neurosci. 31, 120-129, http://dx.doi. org/10.1016/j.tins.2007.12.006

Cahir, M., Ardis, T., Reynolds, G.P., Cooper, S.J., 2007. Acute and chronic tryptophan depletion differentially regulate central 5-HT1A and 5-HT 2A receptor binding in the rat. Psychopharmacology (Berl.) 190, 497-506, http://dx.doi.org/10. 1007/s00213-006-0635-5.

Calder, A.J., Lawrence, A.D., Young, A.W., 2001. Neuropsychology of fear and loathing. Nat. Rev. Neurosci. 2, 352-363, http://dx.doi.org/10.1038/35072584.

Campbell, B.M., Merchant, K.M., 2003. Serotonin 2C receptors within the basolateral amygdala induce acute fear-like responses in an open-field environment. Brain Res. 993, 1-9.

Canli, T., Lesch, K.P., 2007. Long story short: the serotonin transporter in emotion regulation and social cognition. Nat. Neurosci. 10, 1103-1109, http://dx.doi. org/10.1038/nn1964.

Canli, T., Qiu, M., Omura, K., Congdon, E., Haas, B.W., Amin, Z., Herrmann, M.J. Constable, R.T., Lesch, K.P., 2006. Neural correlates of epigenesis. Proc. Natl. Acad. Sci. U. S. A. 103, 16033-16038, http://dx.doi.org/10.1073/pnas. 0601674103.

Canli, T., Congdon, E., Todd Constable, R., Lesch, K.P., 2008. Additive effects of serotonin transporter and tryptophan hydroxylase- 2 gene variation on neural correlates of affective processing. Biol. Psychol. 79, 118-125, http://dx.doi.org/ 10.1016/j.biopsycho.2008.01.004.

Cansev, M., Wurtman, R.J., 2007. Aromatic amino acids in the brain. In: Lajtha, A. (Ed.), Amino Acids and Peptides in the Nervous System, Handbook of Neurochemistry and Molecular Neurobiology, vol. 6. Springer-Verlag, Berlin Heidelberg, pp. 59-97.

Carmichael, S.T., Price, J.L., 1995. Limbic connections of the orbital and media prefrontal cortex in macaque monkeys. J. Comp. Neurol. 363, 615-641, http:// dx.doi.org/10.1002/cne.903630408.

Carpenter, L.L., Anderson, G.M., Pelton, G.H., Gudin, J.A., Kirwin, P.D., Price, L.H. Heninger, G.R., McDougle, C.J., 1998. Tryptophan depletion during continuous CSF sampling in healthy human subjects. Neuropsychopharmacol. Off. Publ. Am. Coll. Neuropsychopharmacol. 19, 26-35, http://dx.doi.org/10.1016/S0893133X(97)00198-X

Carter, C.S., Braver, T.S., Barch, D.M., Botvinick, M.M., Noll, D., Cohen, J.D., 1998. Anterior cingulate cortex, error detection, and the online monitoring of performance. Science 280, 747-749.

Casanovas, J.M., Vilaró, M.T., Mengod, G., Artigas, F., 1999. Differential regulation of somatodendritic serotonin 5-HT1A receptors by 2 -week treatments with the selective agonists alnespirone (S-20499) and

8-hydroxy-2-(di-n-propylamino)tetralin: microdialysis and autoradiographic studies in rat brain. J. Neurochem. 72, 262-272.

Casey, B.J., Oliveri, M.E., Insel, T., 2014. A neurodevelopmental perspective on the research domain criteria (RDoC) framework. Biol. Psychiatry 76, 350-353, http://dx.doi.org/10.1016/j.biopsych.2014.01.006.

Caspi, A., Sugden, K., Moffitt, T.E., Taylor, A., Craig, I.W., Harrington, H., McClay, J., Mill, J., Martin, J., Braithwaite, A., Poulton, R., 2003. Influence of life stress on depression: moderation by a polymorphism in the 5-HTT gene. Science 301 386-389, http://dx.doi.org/10.1126/science.1083968.

Celada, P., Puig, M.V., Casanovas, J.M., Guillazo, G., Artigas, F., 2001. Control of dorsal raphe serotonergic neurons by the medial prefrontal cortex: involvement of serotonin-1A, GABA(A), and glutamate receptors. J. Neurosci. 21, 9917-9929.

Celada, P., Puig, M., Amargós-Bosch, M., Adell, A., Artigas, F., 2004. The therapeutic role of 5-HT1A and 5-HT2A receptors in depression. J. Psychiatry Neurosci. 29 252-265.

Chang, A.S., Chang, S.M., Starnes, D.M., Schroeter, S., Bauman, A.L., Blakely, R.D., 1996. Cloning and expression of the mouse serotonin transporter. Brain Res. Mol. Brain Res. 43, 185-192.

Chen, A., Hough, C.J., Li, H., 2003. Serotonin type II receptor activation facilitates synaptic plasticity via $\mathrm{N}$-methyl-D-aspartate-mediated mechanism in the rat basolateral amygdala. Neuroscience 119, 53-63.

Cloninger, C.R., 2002. The discovery of susceptibility genes for mental disorders. Proc. Natl. Acad. Sci. U. S. A. 99, 13365-13367, http://dx.doi.org/10.1073/pnas. 222532599.

Cools, R., Calder, A.J., Lawrence, A.D., Clark, L., Bullmore, E., Robbins, T.W., 2005 Individual differences in threat sensitivity predict serotonergic modulation of amygdala response to fearful faces. Psychopharmacology (Berl.) 180, 670-679, http://dx.doi.org/10.1007/s00213-005-2215-5.

Cools, R., Roberts, A.C., Robbins, T.W., 2008. Serotoninergic regulation of emotional and behavioural control processes. Trends Cogn. Sci. 12, 31-40, http://dx.doi. org/10.1016/j.tics.2007.10.011.

Coplan, J.D., Gopinath, S., Abdallah, C.G., Berry, B.R., 2014. A neurobiological hypothesis of treatment-resistant depression-mechanisms for selective serotonin reuptake inhibitor non-efficacy. Front. Behav. Neurosci. 8, 189, http://dx.doi.org/10.3389/fnbeh.2014.00189.

Costafreda, S.G., McCann, P., Saker, P., Cole, J.H., Cohen-Woods, S., Farmer, A.E., Aitchison, K.J., McGuffin, P., Fu, C.H.Y., 2013. Modulation of amygdala respons and connectivity in depression by serotonin transporter polymorphism and diagnosis. J. Affect. Disord. 150, 96-103, http://dx.doi.org/10.1016/j.jad.2013. 02.028.

Cowan, W.M., Kopnisky, K.L., Hyman, S.E., 2002. The human genome project and its impact on psychiatry. Annu. Rev. Neurosci. 25, 1-50, http://dx.doi.org/10. 1146/annurev.neuro.25.112701.142853.

Craddock, N., Sklar, P., 2013. Genetics of bipolar disorder. Lancet 381, 1654-1662, http://dx.doi.org/10.1016/S0140-6736(13)60855-7.

Crockett, M.J., Clark, L., Roiser, J.P., Robinson, O.J., Cools, R., Chase, H.W., Ouden, H., den Apergis-Schoute, A., Campbell-Meiklejohn, D., Campbell-Meikeljohn, D., Seymour, B., Sahakian, B.J., Rogers, R.D., Robbins, T.W., 2012. Converging evidence for central 5-HT effects in acute tryptophan depletion. Mol Psychiatry 17, 121-123, http://dx.doi.org/10.1038/mp.2011.106.

Cusi, A.M., Nazarov, A., Holshausen, K., Macqueen, G.M., McKinnon, M.C., 2012. Systematic review of the neural basis of social cognition in patients with mood disorders. J. Psychiatry Neurosci. 37, 154-169, http://dx.doi.org/10.1503/jpn. 100179.

Cuthbert, B.N., Insel, T.R., 2013. Toward the future of psychiatric diagnosis: the seven pillars of RDoC. BMC Med. 11, 126, http://dx.doi.org/10.1186/17417015-11-126.

Cuthbert, B.N., Kozak, M.J., 2013. Constructing constructs for psychopathology: the NIMH research domain criteria. J. Abnorm. Psychol. 122, 928-937, http://dx. doi.org/10.1037/a0034028.

Cuthbert, B.N., 2014. The RDoC framework: facilitating transition from ICD/DSM to dimensional approaches that integrate neuroscience and psychopathology. World Psychiatry 13, 28-35, http://dx.doi.org/10.1002/wps.20087.

Cuthbert, B.N., 2015. Research domain criteria: toward future psychiatric nosologies. Dialogues Clin. Neurosci. 17, 89-97.

Dannlowski, U., Ohrmann, P., Bauer, J., Deckert, J., Hohoff, C., Kugel, H., Arolt, V., Heindel, W., Kersting, A., Baune, B.T., Suslow, T., 2008. 5-HTTLPR biases amygdala activity in response to masked facial expressions in major depression. Neuropsychopharmacology 33, 418-424, http://dx.doi.org/10. 1038/sj.npp.1301411.

Dannlowski, U., Konrad, C., Kugel, H., Zwitserlood, P., Domschke, K., Schöning, S., Ohrmann, P., Bauer, J., Pyka, M., Hohoff, C., Zhang, W., Baune, B.T., Heindel, W. Arolt, V., Suslow, T., 2010. Emotion specific modulation of automatic amygdala responses by 5-HTTLPR genotype. NeuroImage 53, 893-898, http://dx.doi.org/ 10.1016/j.neuroimage.2009.11.073.

Darwin, C., 1965. The Expression of the Emotions in Man and Animals. Univ. of Chicago Press, Chicago (Original work published 1872).

David, S.P., Murthy, N.V., Rabiner, E.A., Munafó, M.R., Johnstone, E.C., Jacob, R. Walton, R.T., Grasby, P.M., 2005. A functional genetic variation of the serotonin (5-HT) transporter affects 5-HT1A receptor binding in humans. J. Neurosci. 25 2586-2590, http://dx.doi.org/10.1523/JNEUROSCI.3769-04.2005.

De Almeida, J., Mengod, G., 2007. Quantitative analysis of glutamatergic and GABAergic neurons expressing 5-HT(2A) receptors in human and monkey prefrontal cortex. J. Neurochem. 103, 475-486, http://dx.doi.org/10.1111/j. 1471-4159.2007.04768.x.

De Mello Cruz, A.P., Pinheiro, G., Alves, S.H., Ferreira, G., Mendes, M., Faria, L. Macedo, C.E., Motta, V., Landeira-Fernandez, J., 2005. Behavioral effects of systemically administered MK-212 are prevented by ritanserin microinfusion into the basolateral amygdala of rats exposed to the elevated plus-maze. Psychopharmacology (Berl.) 182, 345-354, http://dx.doi.org/10.1007/s00213005-0108-2.

Decety, J., Jackson, P.L., 2004. The functional architecture of human empathy. Behav. Cogn. Neurosci. Rev. 3, 71-100, http://dx.doi.org/10.1177/ 1534582304267187.

Del-Ben, C.M., Deakin, J.F.W., McKie, S., Delvai, N.A., Williams, S.R., Elliott, R., Dolan, M., Anderson, I.M., 2005. The effect of citalopram pretreatment on neuronal responses to neuropsychological tasks in normal volunteers: an FMRI study. Neuropsychopharmacology 30, 1724-1734, http://dx.doi.org/10.1038/sj.npp. 1300728.

Del-Ben, C.M., Ferreira, C.A.Q., Alves-Neto, W.C., Graeff, F.G., 2008. Serotonergic modulation of face-emotion recognition. Braz. J. Med. Biol. Res. 41, 263-269.

Demenescu, L.R., Kortekaas, R., den Boer, J.A., Aleman, A., 2010. Impaired attribution of emotion to facial expressions in anxiety and major depression. PLoS One 5, e15058, http://dx.doi.org/10.1371/journal.pone.0015058.

Di Simplicio, M., Norbury, R., Reinecke, A., Harmer, C.J., 2014. Paradoxical effects of short-term antidepressant treatment in fMRI emotional processing models in volunteers with high neuroticism. Psychol. Med. 44, 241-252, http://dx.doi. org/10.1017/S0033291713000731.

Domingos da Silveira da Luz, A.C., Pereira Dias, G., do Nascimento Bevilaqua, M.C., Cocks, G., Gardino, P.F., Thuret, S., Nardi, A.E., 2013. Translational findings on brain-derived neurotrophic factor and anxiety: contributions from basic research to clinical practice. Neuropsychobiology 68, 129-138, http://dx.doi. org/10.1159/000353269.

Domschke, K., Dannlowski, U., 2010. Imaging genetics of anxiety disorders. NeuroImage 53, 822-831, http://dx.doi.org/10.1016/j.neuroimage.2009.11. 042

Domschke, K., Baune, B.T., Havlik, L., Stuhrmann, A., Suslow, T., Kugel, H., Zwanzger, P., Grotegerd, D., Sehlmeyer, C., Arolt, V., Dannlowski, U., 2012. Catechol-O-methyltransferase gene variation: impact on amygdala response to aversive stimuli. NeuroImage 60, 2222-2229, http://dx.doi.org/10.1016/j. neuroimage.2012.02.039.

Drago, A., Serretti, A., 2009. Focus on HTR2C: a possible suggestion for genetic studies of complex disorders. Am. J. Med. Genet. B Neuropsychiatr. Genet. 150B, 601-637, http://dx.doi.org/10.1002/ajmg.b.30864. 
Ebdrup, B.H., Rasmussen, H., Arnt, J., Glenthøj, B., 2011. Serotonin 2A receptor antagonists for treatment of schizophrenia. Expert Opin. Investig. Drugs 20, 1211-1223, http://dx.doi.org/10.1517/13543784.2011.601738.

Egan, M.F., Goldberg, T.E., Kolachana, B.S., Callicott, J.H., Mazzanti, C.M., Straub, R.E. Goldman, D., Weinberger, D.R., 2001. Effect of COMT Val108/158 Met genotype on frontal lobe function and risk for schizophrenia. Proc. Natl. Acad. Sci. U. S. A. 98, 6917-6922, http://dx.doi.org/10.1073/pnas.111134598.

Ekman, P., 1992. An argument for basic emotions. Cogn. Emot. 6, 169-200.

El Mansari, M., Sánchez, C., Chouvet, G., Renaud, B., Haddjeri, N., 2005. Effects of acute and long-term administration of escitalopram and citalopram on serotonin neurotransmission: an in vivo electrophysiological study in rat brain. Neuropsychopharmacology 30, 1269-1277, http://dx.doi.org/10.1038/sj. npp. 1300686.

Evers, E.A.T., Sambeth, A., Ramaekers, J.G., Riedel, W.J., van der Veen, F.M., 2010. The effects of acute tryptophan depletion on brain activation during cognition and emotional processing in healthy volunteers. Curr. Pharm. Des. 16, 1998-2011.

Fisher, P.M., Hariri, A.R., 2013. Identifying serotonergic mechanisms underlying the corticolimbic response to threat in humans. Philos. Trans. R. Soc. Lond. B. Biol. Sci. 368, 20120192, http://dx doi.org/10.1098/rstb.2012.0192.

Fisher, P.M., Meltzer, C.C., Ziolko, S.K., Price, J.C., Moses-Kolko, E.L., Berga, S.L., Hariri, A.R., 2006. Capacity for 5-HT1A-mediated autoregulation predicts amygdala reactivity. Nat. Neurosci. 9, 1362-1363, http://dx.doi.org/10.1038/ nn1780.

Fisher, P.M., Meltzer, C.C., Price, J.C., Coleman, R.L., Ziolko, S.K., Becker, C., Moses-Kolko, E.L., Berga, S.L., Hariri, A.R., 2009. Medial prefrontal cortex 5-HT(2A) density is correlated with amygdala reactivity, response habituation, and functional coupling. Cereb. Cortex 19, 2499-2507, http://dx.doi.org/10 1093/cercor/bhp022.

Fisher, P.M., Price, J.C., Meltzer, C.C., Moses-Kolko, E.L., Becker, C., Berga, S.L., Hariri, A.R., 2011. Medial prefrontal cortex serotonin $1 \mathrm{~A}$ and $2 \mathrm{~A}$ receptor binding interacts to predict threat-related amygdala reactivity. Biol. Mood Anxiety Disord. 1, 2, http://dx.doi.org/10.1186/2045-5380-1-2.

Fisher, P.M., Madsen, M.K., Mc Mahon, B., Holst, K.K., Andersen, S.B., Laursen, H.R., Hasholt, L.F., Siebner, H.R., Knudsen, G.M., 2014. Three-week bright-light intervention has dose-related effects on threat-related corticolimbic reactivity and functional coupling. Biol. Psychiatry 76, 332-339, http://dx.doi.org/10. 1016/j.biopsych.2013.11.031.

Fisher, P.M., Grady, C.L., Madsen, M.K., Strother, S.C., Knudsen, G.M., 2015. 5-HTTLPR differentially predicts brain network responses to emotional faces. Hum. Brain Mapp. 36, 2842-2851, http://dx.doi.org/10.1002/hbm.22811.

Flint, J., Kendler, K.S., 2014. The genetics of major depression. Neuron 81, 484-503, http://dx.doi.org/10.1016/j.neuron.2014.01.027.

Flint, J., Munafò, M.R., 2007. The endophenotype concept in psychiatric genetics. Psychol. Med. 37, 163-180, http://dx.doi.org/10.1017/S0033291706008750.

Frith, C.D., Corcoran, R., 1996. Exploring theory of mind in people with schizophrenia. Psychol. Med. 26, 521-530.

Frith, C.D., Frith, U., 1999. Interacting minds-a biological basis. Science 286, 1692-1695

Frith, U., Frith, C.D., 2003. Development and neurophysiology of mentalizing. Philos. Trans. R. Soc. Lond. B. Biol. Sci. 358, 459-473, http://dx.doi.org/10.1098/ rstb.2002.1218.

Frith, C.D., Frith, U., 2006. The neural basis of mentalizing. Neuron 50, 531-534, http://dx.doi.org/10.1016/j.neuron.2006.05.001.

Fusar-Poli, P., Allen, P., Lee, F., Surguladze, S., Tunstall, N., Fu, C.H.Y., Brammer, M.J., Cleare, A.J., McGuire, P.K., 2007. Modulation of neural response to happy and sad faces by acute tryptophan depletion. Psychopharmacology (Berl.) 193, 31-44, http://dx.doi.org/10.1007/s00213-007-0757-4.

Gallagher, H.L., Frith, C.D., 2003. Functional imaging of theory of mind. Trends Cogn. Sci. 7, 77-83.

Ghashghaei, H.T., Barbas, H., 2002. Pathways for emotion: interactions of prefrontal and anterior temporal pathways in the amygdala of the rhesus monkey. Neuroscience 115, 1261-1279.

Giusti-Rodríguez, P., Sullivan, P.F., 2013. The genomics of schizophrenia: update and implications. J. Clin. Investig. 123, 4557-4563, http://dx.doi.org/10.1172 JCI66031.

Gobbi, G., Murphy, D.L., Lesch, K., Blier, P., 2001. Modifications of the serotonergic system in mice lacking serotonin transporters: an in vivo electrophysiological study. J. Pharmacol. Exp. Ther. 296, 987-995.

Gottesman, I., Gould, T.D., 2003. The endophenotype concept in psychiatry: etymology and strategic intentions. Am. J. Psychiatry 160, 636-645.

Grady, C.L., Siebner, H.R., Hornboll, B., Macoveanu, J., Paulson, O.B., Knudsen, G.M., 2013. Acute pharmacologically induced shifts in serotonin availability abolish emotion-selective responses to negative face emotions in distinct brain networks. Eur. Neuropsychopharmacol. 23, 368-378, http://dx.doi.org/10. 1016/j.euroneuro.2012.06.003.

Gusnard, D.A., Akbudak, E., Shulman, G.L., Raichle, M.E., 2001. Medial prefrontal cortex and self-referential mental activity: relation to a default mode of brain function. Proc. Natl. Acad. Sci. U. S. A. 98, 4259-4264, http://dx.doi.org/10. 1073/pnas.071043098.

Hajós, M., Richards, C.D., Székely, A.D., Sharp, T., 1998. An electrophysiological and neuroanatomical study of the medial prefrontal cortical projection to the midbrain raphe nuclei in the rat. Neuroscience 87, 95-108.

Hajós, M., Hajós-Korcsok, E., Sharp, T., 1999. Role of the medial prefrontal cortex in 5-HT1A receptor-induced inhibition of 5-HT neuronal activity in the rat. Br. J. Pharmacol. 126, 1741-1750, http://dx.doi.org/10.1038/sj.bjp.0702510.
Hardee, J.E., Thompson, J.C., Puce, A., 2008. The left amygdala knows fear: laterality in the amygdala response to fearful eyes. Soc. Cogn. Affect. Neurosci. 3, 47-54, http://dx.doi.org/10.1093/scan/nsn001.

Hariri, A.R., Holmes, A., 2006. Genetics of emotional regulation: the role of the serotonin transporter in neural function. Trends Cogn. Sci. 10, 182-191, http:// dx.doi.org/10.1016/j.tics.2006.02.011.

Hariri, A.R., Bookheimer, S.Y., Mazziotta, J.C., 2000. Modulating emotional responses: effects of a neocortical network on the limbic system. Neuroreport 11, 43-48, http://dx.doi.org/10.1097/00001756-200001170-00009.

Hariri, A.R., Mattay, V.S., Tessitore, A., Kolachana, B., Fera, F., Goldman, D., Egan, M.F., Weinberger, D.R., 2002. Serotonin transporter genetic variation and the response of the human amygdala. Science $297,400-403$, http://dx.doi.org/10 $1126 /$ science.1071829.

Hariri, A.R., Drabant, E.M., Munoz, K.E., Kolachana, B.S., Mattay, V.S., Egan, M.F. Weinberger, D.R., 2005. A susceptibility gene for affective disorders and the response of the human amygdala. Arch. Gen. Psychiatry 62, 146-152, http://dx doi.org/10.1001/archpsyc.62.2.146.

Hariri, A.R., Drabant, E.M., Weinberger, D.R., 2006. Imaging genetics: perspectives from studies of genetically driven variation in serotonin function and corticolimbic affective processing. Biol. Psychiatry 59, 888-897, http://dx.doi. $\operatorname{org} / 10.1016 /$ j.biopsych.2005.11.005.

Harmer, C.J., Mackay, C.E., Reid, C.B., Cowen, P.J., Goodwin, G.M., 2006. Antidepressant drug treatment modifies the neural processing of nonconscious threat cues. Biol. Psychiatry 59, 816-820, http://dx.doi.org/10. 1016/j.biopsych.2005.10.015.

Harmer, C.J., 2008. Serotonin and emotional processing: does it help explain antidepressant drug action? Neuropharmacology 55, 1023-1028, http://dx.doi org/10.1016/j.neuropharm.2008.06.036.

Harrison, P.J., Weinberger, D.R., 2005. Schizophrenia genes, gene expression, and neuropathology: on the matter of their convergence. Mol. Psychiatry 10, 40-68, http://dx.doi.org/10.1038/sj.mp.4001558.

Haxby, J.V., Ungerleider, L.G., Clark, V.P., Schouten, J.L., Hoffman, E.A., Martin, A., 1999. The effect of face inversion on activity in human neural systems for face and object perception. Neuron 22, 189-199.

Haxby, J.V., Hoffman, E.A., Gobbini, M.I., 2000. The distributed human neural system for face perception. Trends Cogn. Sci. 4, 223-233.

Hay-Schmidt, A., 2000. The evolution of the serotonergic nervous system. Proc. Biol. Sci. 267, 1071-1079, http://dx.doi.org/10.1098/rspb.2000.1111.

Heils, A., Teufel, A., Petri, S., Stober, G., Riederer, P., Bengel, D., Lesch, K.P., 1996 Allelic variation of human serotonin transporter gene expression. J. Neurochem. 66, 2621-2624.

Heinz, A., Smolka, M.N., 2006. The effects of catechol O-methyltransferase genotype on brain activation elicited by affective stimuli and cognitive tasks. Rev. Neurosci. 17, 359-367.

Heinz, A., Jones, D.W., Mazzanti, C., Goldman, D., Ragan, P., Hommer, D., Linnoila, M., Weinberger, D.R., 2000. A relationship between serotonin transporter genotype and in vivo protein expression and alcohol neurotoxicity. Biol. Psychiatry 47, 643-649.

Heinz, A., Braus, D.F., Smolka, M.N., Wrase, J., Puls, I., Hermann, D., Klein, S., Grusser, S.M., Flor, H., Schumann, G., Mann, K., Buchel, C., 2005. Amygdala-prefrontal coupling depends on a genetic variation of the serotonin transporter. Nat. Neurosci. 8, 20-21, http://dx.doi.org/10.1038/nn1366.

Hernández, F., Gómez de Barreda, E., Fuster-Matanzo, A., Lucas, J.J., Avila, J., 2010 GSK3: a possible link between beta amyloid peptide and tau protein. Exp. Neurol. 223, 322-325, http://dx.doi.org/10.1016/j.expneurol.2009.09.011.

Hervás, I., Vilaró, M.T., Romero, L, Scorza, M.C. Mengod, G., Artigas, F, 2001. Desensitization of 5-HT(1A) autoreceptors by a low chronic fluoxetine dose effect of the concurrent administration of WAY-100635. Neuropsychopharmacology 24, 11-20, http://dx.doi.org/10.1016/S0893$133 \mathrm{X}(00) 00175-5$.

Hoertnagl, C.M. Hofer, A. 2014. Social cognition in serious mental illness. Curr. Opin. Psychiatry 27, 197-202, http://dx.doi.org/10.1097/YCO. 0000000000000055

Holmes, A., Lit, Q., Murphy, D.L., Gold, E., Crawley, J.N., 2003. Abnormal anxiety-related behavior in serotonin transporter null mutant mice: the influence of genetic background. Genes Brain Behav. 2, 365-380.

Honey, G., Bullmore, E., 2004. Human pharmacological MRI. Trends Pharmacol. Sci. 25, 366-374, http://dx.doi.org/10.1016/j.tips.2004.05.009.

Hornboll, B., Macoveanu, J., Rowe, J., Elliott, R., Paulson, O.B., Siebner, H.R., Knudsen, G.M., 2013. Acute serotonin 2 A receptor blocking alters the processing of fearful faces in the orbitofrontal cortex and amygdala. J. Psychopharmacol. 27, 903-914, http://dx.doi.org/10.1177/0269881113494106.

Hoyer, D., Clarke, D.E., Fozard, J.R., Hartig, P.R., Martin, G.R., Mylecharane, E.J., Saxena, P.R., Humphrey, P.P., 1994. International union of pharmacology classification of receptors for 5-hydroxytryptamine (Serotonin). Pharmacol. Rev, 46, 157-203.

Hoyer, D., Hannon, J.P., Martin, G.R., 2002. Molecular, pharmacological and functional diversity of 5-HT receptors. Pharmacol. Biochem. Behav. 71, 533-554.

Hu, X-Z. Lipsky, R.H., Zhu, G, Akhtar, L.A., Taubman, J., Greenberg, B.D., Xu, K. Arnold, P.D., Richter, M.A., Kennedy, J.L., Murphy, D.L., Goldman, D., 2006. Serotonin transporter promoter gain-of-function genotypes are linked to obsessive-compulsive disorder. Am. J. Hum. Genet. 78, 815-826, http://dx.doi. org/10.1086/503850.

Hyman, S.E., 2000. The genetics of mental illness: implications for practice. Bull. World Health Organ. 78, 455-463. 
Iadecola, C., 2004. Neurovascular regulation in the normal brain and in Alzheimer's disease. Nat. Rev. Neurosci. 5, 347-360, http://dx.doi.org/10.1038/nrn1387.

Iarocci, G., Yager, J., Elfers, T., 2007. What gene-environment interactions can tell us about social competence in typical and atypical populations. Brain Cogn. 65 , 112-127, http://dx.doi.org/10.1016/j.bandc.2007.01.008.

Iidaka, T., Ozaki, N., Matsumoto, A., Nogawa, J., Kinoshita, Y., Suzuki, T., Iwata, N., Yamamoto, Y., Okada, T., Sadato, N., 2005. A variant C178T in the regulatory region of the serotonin receptor gene HTR3A modulates neural activation in the human amygdala. J. Neurosci. 25, 6460-6466, http://dx.doi.org/10.1523/ JNEUROSCI.5261-04.2005.

Insel, T., Cuthbert, B., Garvey, M., Heinssen, R., Pine, D.S., Quinn, K., Sanislow, C., Wang, P., 2010. Research domain criteria (RDoC): toward a new classification framework for research on mental disorders. Am. J. Psychiatry 167, 748-751, http://dx.doi.org/10.1176/appi.ajp.2010.09091379.

Insel, T.R., 2014. The NIMH research domain criteria (RDoC) project: precision medicine for psychiatry. Am. J. Psychiatry 171, 395-397, http://dx.doi.org/10. 1176/appi.ajp.2014.14020138

Invernizzi, R., Belli, S., Samanin, R. 1992. Citalopram's ability to increase the extracellular concentrations of serotonin in the dorsal raphe prevents the drug's effect in the frontal cortex. Brain Res. 584, 322-324.

Jacobs, B.L., Azmitia, E.C., 1992. Structure and function of the brain serotonin system. Physiol. Rev. 72, 165-229.

Jakab, R.L., Goldman-Rakic, P.S., 1998. 5-Hydroxytryptamine2A serotonin receptors in the primate cerebral cortex: possible site of action of hallucinogenic and antipsychotic drugs in pyramidal cell apical dendrites. Proc. Natl. Acad. Sci. U. S. A. 95, 735-740.

Jankowski, M.P., Sesack, S.R., 2004. Prefrontal cortical projections to the rat dorsa raphe nucleus: ultrastructural features and associations with serotonin and gamma-aminobutyric acid neurons. J. Comp. Neurol. 468, 518-529, http://dx. doi.org/10.1002/cne.10976.

Jonassen, R., Foss Haug, K.B., Endestad, T., Bentsen, H., Grimholt, R.M., Landrø, N.I. 2013. Associations between serotonin transporter polymorphisms and cognitive processing applying the Emo 1-back task. Cogn. Emot. 27, 465-473, http://dx.doi.org/10.1080/02699931.2012.726213.

Kandel, E.R., Squire, L.R., 2000. Neuroscience: breaking down scientific barriers to the study of brain and mind. Science 290, 1113-1120.

Kandel, E.R., 1998. A new intellectual framework for psychiatry. Am. J. Psychiatry 155, 457-469.

Karg, K., Burmeister, M., Shedden, K., Sen, S., 2011. The serotonin transporter promoter variant (5-HTTLPR), stress, and depression meta-analysis revisited: evidence of genetic moderation. Arch. Gen. Psychiatry 68, 444-454, http://dx doi.org/10.1001/archgenpsychiatry.2010.189.

Karlović, D., Karlović, D., 2013. Serotonin transporter gene (5-HTTLPR) polymorphism and efficacy of selective serotonin reuptake inhibitors-do we have sufficient evidence for clinical practice. Acta Clin. Croat. 52, 353-362.

Karlsgodt, K.H., Bachman, P., Winkler, A.M., Bearden, C.E., Glahn, D.C., 2011 Genetic influence on the working memory circuitry: behavior, structure, function and extensions to illness. Behav. Brain Res. 225, 610-622, http://dx. doi.org/10.1016/j.bbr.2011.08.016.

Kendler, K.S., Neale, M.C., 2010. Endophenotype: a conceptual analysis. Mol. Psychiatry 15, 789-797, http://dx.doi.org/10.1038/mp.2010.8.

Kilford, E.J., Dumontheil, I., Wood, N.W., Blakemore, S.-J., 2014. Influence of COMT genotype and affective distractors on the processing of self-generated thought. Soc. Cogn. Affect. Neurosci., http://dx.doi.org/10.1093/scan/nsu118.

Kilpatrick, L.A., Labus, J.S., Coveleskie, K., Hammer, C., Rappold, G., Tillisch, K., Bueller, J.A., Suyenobu, B., Jarcho, J.M., McRoberts, J.A., Niesler, B., Mayer, E.A. 2011. The HTR3A polymorphism c. $-42 \mathrm{C}>\mathrm{T}$ is associated with amygdala responsiveness in patients with irritable bowel syndrome. Gastroenterology 140, 1943-1951, http://dx.doi.org/10.1053/j.gastro.2011.03.011.

Kim, D.-K., Tolliver, T.J., Huang, S.-J., Martin, B.J., Andrews, A.M., Wichems, C. Holmes, A., Lesch, K.-P., Murphy, D.L., 2005. Altered serotonin synthesis, turnover and dynamic regulation in multiple brain regions of mice lacking the serotonin transporter. Neuropharmacology 49, 798-810, http://dx.doi.org/10. 1016/j.neuropharm.2005.08.010.

Kiyasova, V., Gaspar, P., 2011. Development of raphe serotonin neurons from specification to guidance. Eur. J. Neurosci. 34, 1553-1562, http://dx.doi.org/10. $1111 /$ j.1460-9568.2011.07910.x.

Klein, A.B., Santini, M.A., Aznar, S., Knudsen, G.M., Rios, M., 2010. Changes in 5-HT2A-mediated behavior and 5-HT2A- and 5-HT1A receptor binding and expression in conditional brain-derived neurotrophic factor knock-out mice. Neuroscience 169, 1007-1016, http://dx.doi.org/10.1016/j.neuroscience.2010. 05.054 .

Klomp, A., van Wingen, G.A., de Ruiter, M.B., Caan, M.W.A., Denys, D., Reneman, L., 2013. Test-retest reliability of task-related pharmacological MRI with a single-dose oral citalopram challenge. NeuroImage 75, 108-116, http://dx.doi. org/10.1016/j.neuroimage.2013.03.002.

Klumpp, H., Fitzgerald, D.A., Cook, E., Shankman, S.A., Angstadt, M., Phan, K.L., 2014. Serotonin transporter gene alters insula activity to threat in social anxiety disorder. Neuroreport 25, 926-931, http://dx.doi.org/10.1097/WNR. 0000000000000210.

Kohler, C.G., Walker, J.B., Martin, E.A., Healey, K.M., Moberg, P.J., 2010. Facial emotion perception in schizophrenia: a meta-analytic review. Schizophr. Bull 36, 1009-1019, http://dx.doi.org/10.1093/schbul/sbn192.

Kringelbach, M.L., Rolls, E.T., 2004. The functional neuroanatomy of the human orbitofrontal cortex: evidence from neuroimaging and neuropsychology. Prog. Neurobiol. 72, 341-372, http://dx.doi.org/10.1016/j.pneurobio.2004.03.006.
Kroes, M.C.W., van Wingen, G.A., Wittwer, J., Mohajeri, M.H., Kloek, J., Fernández, G., 2014. Food can lift mood by affecting mood-regulating neurocircuits via a serotonergic mechanism. NeuroImage 84, 825-832, http://dx.doi.org/10.1016/ j.neuroimage.2013.09.041.

Lee, B.-T., Ham, B.-J., 2008. Serotonergic genes and amygdala activity in response to negative affective facial stimuli in Korean women. Genes Brain Behav. 7, 899-905, http://dx.doi.org/10.1111/j.1601-183X.2008.00429.x.

Lee, K.H., Farrow, T.F.D., Spence, S.A., Woodruff, P.W.R., 2004. Social cognition, brain networks and schizophrenia. Psychol. Med. 34, 391-400.

Lee, M., Bailer, U.F., Frank, G.K., Henry, S.E., Meltzer, C.C., Price, J.C., Mathis, C.A., Putnam, K.T., Ferrell, R.E., Hariri, A.R., Kaye, W.H., 2005. Relationship of a 5-HT transporter functional polymorphism to 5-HT1A receptor binding in healthy women. Mol. Psychiatry 10, 715-716, http://dx.doi.org/10.1038/sj.mp. 4001680.

Leppänen, J.M., 2006. Emotional information processing in mood disorders: a review of behavioral and neuroimaging findings. Curr. Opin. Psychiatry 19, 34-39, http://dx.doi.org/10.1097/01.yco.0000191500.46411.00.

Lerer, B., Macciardi, F., Segman, R.H., Adolfsson, R., Blackwood, D., Blairy, S., Del Favero, J., Dikeos, D.G., Kaneva, R., Lilli, R., Massat, I., Milanova, V., Muir, W., Noethen, M., Oruc, L., Petrova, T., Papadimitriou, G.N., Rietschel, M., Serretti, A., Souery, D., Van Gestel, S., Van Broeckhoven, C., Mendlewicz, J., 2001. Variability of 5-HT2C receptor cys23ser polymorphism among European populations and vulnerability to affective disorder. Mol. Psychiatry 6, 579-585, http://dx.doi. org/10.1038/sj.mp.4000883.

Lesch, K.P., Bengel, D., Heils, A., Sabol, S.Z., Greenberg, B.D., Petri, S., Benjamin, J., Muller, C.R., Hamer, D.H., Murphy, D.L., 1996. Association of anxiety-related traits with a polymorphism in the serotonin transporter gene regulatory region. Science 274, 1527-1531.

Leysen, J.E., 2004. 5-HT2 receptors. Curr. Drug Targets CNS Neurol. Disord. 3, 11-26.

Li, Q., Wichems, C.H., Ma, L., Van de Kar, L.D., Garcia, F., Murphy, D.L., 2003. Brain region-specific alterations of 5-HT2A and 5-HT2C receptors in serotonin transporter knockout mice. J. Neurochem. 84, 1256-1265.

Lieben, C.K.J., Blokland, A., Westerink, B., Deutz, N.E.P., 2004. Acute tryptophan and serotonin depletion using an optimized tryptophan-free protein-carbohydrate mixture in the adult rat. Neurochem. Int. 44, 9-16.

Logue, S.F., Gould, T.J., 2014. The neural and genetic basis of executive function: attention, cognitive flexibility, and response inhibition. Pharmacol. Biochem. Behav. 123, 45-54, http://dx.doi.org/10.1016/j.pbb.2013.08.007.

Lonsdorf, T.B., Golkar, A., Lindstöm, K.M., Fransson, P., Schalling, M., Ohman, A., Ingvar, M., 2011. 5-HTTLPR and COMTval158met genotype gate amygdala reactivity and habituation. Biol. Psychol. 87, 106-112, http://dx.doi.org/10. 1016/j.biopsycho.2011.02.014.

Lu, B., Nagappan, G., Lu, Y., 2014. BDNF and synaptic plasticity, cognitive function, and dysfunction. Handb. Exp. Pharmacol. 220, 223-250, http://dx.doi.org/10. 1007/978-3-642-45106-5_9.

Ma, Y., Li, B., Wang, C., Zhang, W., Rao, Y., Han, S., 2015. Allelic variation in 5-HTTLPR and the effects of citalopram on the emotional neural network. Br. J. Psychiatry, http://dx.doi.org/10.1192/bjp.bp.114.150128.

Ma, Y., 2015. Neuropsychological mechanism underlying antidepressant effect: a systematic meta-analysis. Mol. Psychiatry 20, 311-319, http://dx.doi.org/10. 1038/mp.2014.24.

Maren, S., Quirk, G.J., 2004. Neuronal signalling of fear memory. Nat. Rev. Neurosci. 5, 844-852, http://dx.doi.org/10.1038/nrn1535.

Matthes, S., Mosienko, V., Bashammakh, S., Alenina, N., Bader, M., 2010. Tryptophan hydroxylase as novel target for the treatment of depressive disorders. Pharmacology 85, 95-109, http://dx.doi.org/10.1159/000279322.

Meek, S.E., Lemery-Chalfant, K., Jahromi, L.B., Valiente, C., 2013. A review of gene-environment correlations and their implications for autism: a conceptual model. Psychol. Rev. 120, 497-521, http://dx.doi.org/10.1037/a0033139.

Meyer-Lindenberg, A., Weinberger, D.R., 2006. Intermediate phenotypes and genetic mechanisms of psychiatric disorders. Nat. Rev. Neurosci. 7, 818-827, http://dx.doi.org/10.1038/nrn1993.

Meyer-Lindenberg, A., Hariri, A.R., Munoz, K.E., Mervis, C.B., Mattay, V.S., Morris, C.A., Berman, K.F., 2005. Neural correlates of genetically abnormal social cognition in Williams syndrome. Nat. Neurosci. 8, 991-993, http://dx.doi.org/ $10.1038 / \mathrm{nn} 1494$

Meyer-Lindenberg, A., Buckholtz, J.W., Kolachana, B., Hariri, A.R., Pezawas, L., Blasi, G., Wabnitz, A., Honea, R., Verchinski, B., Callicott, J.H., Egan, M., Mattay, V., Weinberger, D.R., 2006. Neural mechanisms of genetic risk for impulsivity and violence in humans. Proc. Natl. Acad. Sci. U. S. A. 103, 6269-6274, http://dx.doi. org/10.1073/pnas.0511311103.

Meyer-Lindenberg, A., 2012. The future of fMRI and genetics research. Neurolmage 62, 1286-1292, http://dx.doi.org/10.1016/j.neuroimage.2011.10.063.

Mier, D., Kirsch, P., Meyer-Lindenberg, A., 2010a. Neural substrates of pleiotropic action of genetic variation in COMT: a meta-analysis. Mol. Psychiatry 15, 918-927, http://dx.doi.org/10.1038/mp.2009.36.

Mier, D., Lis, S., Neuthe, K., Sauer, C., Esslinger, C., Gallhofer, B., Kirsch, P., 2010 b. The involvement of emotion recognition in affective theory of mind. Psychophysiology 47, 1028-1039, http://dx.doi.org/10.1111/j.1469-8986. 2010.01031.x.

Mier, D., Sauer, C., Lis, S., Esslinger, C., Wilhelm, J., Gallhofer, B., Kirsch, P., 2010c. Neuronal correlates of affective theory of mind in schizophrenia out-patients: evidence for a baseline deficit. Psychol. Med. 40, 1607-1617, http://dx.doi.org/ $10.1017 /$ S0033291709992133. 
Miner, L.a.H., Backstrom, J.R., Sanders-Bush, E., Sesack, S.R., 2003. Ultrastructural localization of serotonin2A receptors in the middle layers of the rat prelimbic prefrontal cortex. Neuroscience 116, 107-117.

Moore, R.Y., Halaris, A.E., Jones, B.E., 1978. Serotonin neurons of the midbrain raphe: ascending projections. J. Comp. Neurol. 180, 417-438, http://dx.doi.org $10.1002 /$ cne. 901800302

Moreno, F.A., McGavin, C., Malan, T.P., Gelenberg, A.J., Heninger, G.R., Mathé, A.A., Delgado, P.L., 2000. Tryptophan depletion selectively reduces CSF 5-HT metabolites in healthy young men: results from single lumbar puncture sampling technique. Int. J. Neuropsychopharmacol. 3, 277-283, http://dx.doi. org/10.1017/S1461145700002133.

Morris, J.S., Frith, C.D., Perrett, D.I., Rowland, D., Young, A.W., Calder, A.J., Dolan, R.J., 1996. A differential neural response in the human amygdala to fearful and happy facial expressions. Nature 383, 812-815, http://dx.doi.org/10.1038/ 383812a0.

Morris, R.W., Weickert, C.S., Loughland, C.M., 2009. Emotional face processing in schizophrenia. Curr. Opin. Psychiatry 22, 140-146, http://dx.doi.org/10.1097/ YCO.0b013e328324f895.

Munafò, M.R., Clark, T.G., Roberts, K.H., Johnstone, E.C., 2006. Neuroticism mediates the association of the serotonin transporter gene with lifetime major depression. Neuropsychobiology 53, 1-8, http://dx.doi.org/10.1159/ 000089915.

Munafò, M.R., Brown, S.M., Hariri, A.R., 2008. Serotonin transporter (5-HTTLPR) genotype and amygdala activation: a meta-analysis. Biol. Psychiatry 63 , 852-857, http://dx.doi.org/10.1016/j.biopsych.2007.08.016.

Murphy, S.E., Norbury, R., O'sullivan, U., Cowen, P.J., Harmer, C.J., 2009. Effect of a single dose of citalopram on amygdala response to emotional faces. $\mathrm{Br}$. J. Psychiatry 194, 535-540, http://dx.doi.org/10.1192/bjp.bp.108.056093.

Murphy, S.E., Norbury, R., Godlewska, B.R., Cowen, P.J., Mannie, Z.M., Harmer, C.J., Munafò, M.R., 2013. The effect of the serotonin transporter polymorphism (5-HTTLPR) on amygdala function: a meta-analysis. Mol. Psychiatry 18, 512-520, http://dx.doi.org/10.1038/mp.2012.19.

Nakamura, K., Hasegawa, H., 2007. Developmental role of tryptophan hydroxylase in the nervous system. Mol. Neurobiol. 35, 45-54.

Nakamura, M., Ueno, S., Sano, A., Tanabe, H., 2000. The human serotonin transporter gene linked polymorphism (5-HTTLPR) shows ten novel allelic variants. Mol. Psychiatry 5, 32-38

Nakamura, A., Maess, B., Knösche, T.R., Friederici, A.D., 2014. Different hemispheric roles in recognition of happy expressions. PLoS One 9, e88628, http://dx.doi. org/10.1371/journal.pone.0088628.

Naudts, K.H., Azevedo, R.T., David, A.S., van Heeringen, K., Gibbs, A.A., 2012. Epistasis between 5-HTTLPR and ADRA2B polymorphisms influences attentional bias for emotional information in healthy volunteers. Int. J. Neuropsychopharmacol. 15, 1027-1036, http://dx.doi.org/10.1017/ S1461145711001295.

Navailles, S., De Deurwaerdère, P., 2011. Presynaptic control of serotonin on striatal dopamine function. Psychopharmacology (Berl.) 213, 213-242, http:// dx.doi.org/10.1007/s00213-010-2029-y.

Nishizawa, S., Benkelfat, C., Young, S.N., Leyton, M., Mzengeza, S., de Montigny, C., Blier, P., Diksic, M., 1997. Differences between males and females in rates of serotonin synthesis in human brain. Proc. Natl. Acad. Sci. U. S. A. 94 5308-5313.

Norbury, R., Taylor, M.J., Selvaraj, S., Murphy, S.E., Harmer, C.J., Cowen, P.J., 2009. Short-term antidepressant treatment modulates amygdala response to happy faces. Psychopharmacology (Berl.) 206, 197-204, http://dx.doi.org/10.1007/ S00213-009-1597-1.

O’Nions, E.J.P., Dolan, R.J., Roiser, J.P., 2011. Serotonin transporter genotype modulates subgenual response to fearful faces using an incidental task. J. Cogn. Neurosci. 23, 3681-3693, http://dx.doi.org/10.1162/jocn_a_00055.

Olivier, B., 2015. Serotonin: a never-ending story. Eur. J. Pharmacol. 753, 2-18, http://dx.doi.org/10.1016/j.ejphar.2014.10.031.

Outhred, T., Das, P., Dobson-Stone, C., Griffiths, K., Felmingham, K.L., Bryant, R.A., Malhi, G., Kemp, A.H., 2012. The functional epistasis of 5-HTTLPR and BDNF Val66Met on emotion processing: a preliminary study. Brain Behav. 2, 778-788, http://dx.doi.org/10.1002/brb3.99.

Pardridge, W.M., 1979. The role of blood-brain barrier transport of tryptophan and other neutral amino acids in the regulation of substrate-limited pathways of brain amino acid metabolism. J. Neural Transm., 43-54.

Passamonti, L., Crockett, M.J., Apergis-Schoute, A.M., Clark, L., Rowe, J.B., Calder, A.J., Robbins, T.W., 2012. Effects of acute tryptophan depletion on prefrontal-amygdala connectivity while viewing facial signals of aggression. Biol. Psychiatry 71, 36-43, http://dx.doi.org/10.1016/j.biopsych.2011.07.033.

Paus, T., 2001. Primate anterior cingulate cortex: where motor control, drive and cognition interface. Nat. Rev. Neurosci. 2, 417-424, http://dx.doi.org/10.1038/ 35077500.

Persico, A.M., Napolioni, V., 2013. Autism genetics. Behav. Brain Res. 251, 95-112, http://dx.doi.org/10.1016/j.bbr.2013.06.012.

Pezawas, L., Meyer-Lindenberg, A., Drabant, E.M., Verchinski, B.A., Munoz, K.E., Kolachana, B.S., Egan, M.F., Mattay, V.S., Hariri, A.R., Weinberger, D.R., 2005. 5-HTTLPR polymorphism impacts human cingulate-amygdala interactions: a genetic susceptibility mechanism for depression. Nat. Neurosci. 8, 828-834, http://dx.doi.org/10.1038/nn1463.

Pezawas, L., Meyer-Lindenberg, A., Goldman, A.L., Verchinski, B.A., Chen, G., Kolachana, B.S., Egan, M.F., Mattay, V.S., Hariri, A.R., Weinberger, D.R., 2008. Evidence of biologic epistasis between BDNF and SLC6A4 and implications for depression. Mol. Psychiatry 13, 709-716, http://dx.doi.org/10.1038/mp.2008. 32.

Phillips, M.L., Young, A.W., Senior, C., Brammer, M., Andrew, C., Calder, A.J., Bullmore, E.T., Perrett, D.I., Rowland, D., Williams, S.C., Gray, J.A., David, A.S., 1997. A specific neural substrate for perceiving facial expressions of disgust. Nature 389, 495-498, http://dx.doi.org/10.1038/39051.

Porcelli, S., Fabbri, C., Serretti, A., 2012. Meta-analysis of serotonin transporter gene promoter polymorphism (5-HTTLPR) association with antidepressan efficacy. Eur. Neuropsychopharmacol. 22, 239-258, http://dx.doi.org/10.1016/ j.euroneuro.2011.10.003.

Price, L.H., Malison, R.T., McDougle, C.J., McCance-Katz, E.F., Owen, K.R., Heninger, G.R., 1997. Neurobiology of tryptophan depletion in depression: effects of m-chlorophenylpiperazine (mCPP). Neuropsychopharmacology 17, 342-350, http://dx.doi.org/10.1016/S0893-133X(97)00084-5.

Price, L.H., Malison, R.T., McDougle, C.J., Pelton, G.H., Heninger, G.R., 1998. The neurobiology of tryptophan depletion in depression: effects of intravenous tryptophan infusion. Biol. Psychiatry 43, 339-347.

Quirk, G.J., Garcia, R., González-Lima, F., 2006. Prefrontal mechanisms in extinction of conditioned fear. Biol. Psychiatry 60, 337-343, http://dx.doi.org/10.1016/j. biopsych.2006.03.010.

Raghanti, M.A., Stimpson, C.D., Marcinkiewicz, J.L., Erwin, J.M., Hof, P.R., Sherwood, C.C., 2008. Differences in cortical serotonergic innervation among humans, chimpanzees, and macaque monkeys: a comparative study. Cereb. Cortex 18 584-597, http://dx.doi.org/10.1093/cercor/bhm089.

Ramamoorthy, S., Bauman, A.L., Moore, K.R., Han, H., Yang-Feng, T., Chang, A.S., Ganapathy, V., Blakely, R.D., 1993. Antidepressant- and cocaine-sensitive human serotonin transporter: molecular cloning expression, and chromosomal localization. Proc. Natl. Acad. Sci. U. S. A. 90, 2542-2546.

Rauch, S.L., Shin, L.M., Phelps, E.A., 2006. Neurocircuitry models of posttraumatic stress disorder and extinction: human neuroimaging research-past, present, and future. Biol. Psychiatry 60, 376-382, http://dx.doi.org/10.1016/j.biopsych. 2006.06.004.

Reilly, J.G., McTavish, S.F., Young, A.H., 1997. Rapid depletion of plasma tryptophan: a review of studies and experimental methodology. J. Psychopharmacol. 11, 381-392.

Riad, M., Garcia, S., Watkins, K.C., Jodoin, N., Doucet, E., Langlois, X., el Mestikawy, S., Hamon, M., Descarries, L., 2000. Somatodendritic localization of 5-HT1A and preterminal axonal localization of 5-HT1B serotonin receptors in adult rat brain. J. Comp. Neurol. 417, 181-194.

Richtand, N.M., McNamara, R.K., 2008. Serotonin and dopamine interactions in psychosis prevention. Prog. Brain Res. 172, 141-153, http://dx.doi.org/10. 1016/S0079-6123(08)00907-2.

Risch, N., Herrell, R., Lehner, T., Liang, K.-Y., Eaves, L., Hoh, J., Griem, A., Kovacs, M., Ott, J., Merikangas, K.R., 2009. Interaction between the serotonin transporter gene (5-HTTLPR), stressful life events, and risk of depression: a meta-analysis. JAMA 301, 2462-2471, http://dx.doi.org/10.1001/jama.2009.878.

Roberts, C., Price, G.W., Middlemiss, D.N., 2001. Ligands for the investigation of 5-HT autoreceptor function. Brain Res. Bull. 56, 463-469.

Robinson, O.J., Overstreet, C., Allen, P.S., Letkiewicz, A., Vytal, K., Pine, D.S., Grillon, C., 2013. The role of serotonin in the neurocircuitry of negative affective bias: serotonergic modulation of the dorsal medial prefrontal-amygdala aversive amplification circuit. NeuroImage 78, 217-223, http://dx.doi.org/10.1016/j. neuroimage.2013.03.075.

Rolls, E.T., Grabenhorst, F., 2008. The orbitofrontal cortex and beyond: from affect to decision-making. Prog. Neurobiol. 86, 216-244, http://dx.doi.org/10.1016/j. pneurobio.2008.09.001.

Romero, L., Bel, N., Artigas, F., de Montigny, C., Blier, P., 1996. Effect of pindolol on the function of pre- and postsynaptic 5-HT1A receptors: in vivo microdialysis and electrophysiological studies in the rat brain. Neuropsychopharmacology 15, 349-360, http://dx.doi.org/10.1016/0893-133X(95)00240-E.

Rule, R.R., Shimamura, A.P., Knight, R.T., 2002. Orbitofrontal cortex and dynamic filtering of emotional stimuli. Cogn. Affect. Behav. Neurosci. 2, 264-270.

Santana, N., Bortolozzi, A., Serrats, J., Mengod, G., Artigas, F., 2004. Expression of serotonin1 A and serotonin2A receptors in pyramidal and GABAergic neurons of the rat prefrontal cortex. Cereb. Cortex 14, 1100-1109, http://dx.doi.org/10. 1093/cercor/bhh070.

Sauer, C., Montag, C., Wörner, C., Kirsch, P., Reuter, M., 2012. Effects of a common variant in the CD38 gene on social processing in an oxytocin challenge study: possible links to autism. Neuropsychopharmacology 37, 1474-1482, http://dx. doi.org/10.1038/npp.2011.333.

Savitz, J., Lucki, I., Drevets, W.C., 2009. 5-HT(1A) receptor function in major depressive disorder. Prog. Neurobiol. 88, 17-31, http://dx.doi.org/10.1016/j. pneurobio.2009.01.009.

Scharinger, C., Rabl, U., Sitte, H.H., Pezawas, L., 2010. Imaging genetics of mood disorders. Neurolmage 53, 810-821, http://dx.doi.org/10.1016/j.neuroimage. 2010.02.019.

Schinka, J.A., Busch, R.M., Robichaux-Keene, N., 2004. A meta-analysis of the association between the serotonin transporter gene polymorphism (5-HTTLPR) and trait anxiety. Mol. Psychiatry 9, 197-202, http://dx.doi.org/10. 1038/sj.mp.4001405.

Seifuddin, F., Pirooznia, M., Judy, J.T., Goes, F.S., Potash, J.B., Zandi, P.P., 2013. Systematic review of genome-wide gene expression studies of bipolar disorder. BMC Psychiatry 13, 213, http://dx.doi.org/10.1186/1471-244X-13-213.

Serretti, A., Kato, M., De Ronchi, D., Kinoshita, T., 2007. Meta-analysis of serotonin transporter gene promoter polymorphism (5-HTTLPR) association with 
selective serotonin reuptake inhibitor efficacy in depressed patients. Mol. Psychiatry 12, 247-257, http://dx.doi.org/10.1038/sj.mp.4001926.

Shimamura, A.P., 2000. The role of the prefrontal cortex in dynamic filtering. Psychobiology 28, 207-218.

Skuse, D.H., Gallagher, L., 2011. Genetic influences on social cognition. Pediatr. Res. 69, 85R-91R, http://dx.doi.org/10.1203/PDR.0b013e318212f562.

Smits, K.M., Smits, L.J.M., Schouten, J.S.a.G, Stelma, F.F., Nelemans, P., Prins, M.H., 2004. Influence of SERTPR and STin2 in the serotonin transporter gene on the effect of selective serotonin reuptake inhibitors in depression: a systematic review. Mol. Psychiatry 9, 433-441, http://dx.doi.org/10.1038/sj.mp.4001488.

Sotelo, C., Cholley, B., El Mestikawy, S., Gozlan, H., Hamon, M., 1990. Direct immunohistochemical evidence of the existence of 5-HT1A autoreceptors on serotoninergic neurons in the midbrain raphe nuclei. Eur. J. Neurosci. 2, 11441154

Stefanacci, L., Amaral, D.G., 2002. Some observations on cortical inputs to the macaque monkey amygdala: an anterograde tracing study. J. Comp. Neurol. 451, 301-323, http://dx.doi.org/10.1002/cne.10339.

Stein, C., Davidowa, H., Albrecht, D., 2000. 5-HT(1A) receptor-mediated inhibition and 5-HT(2) as well as 5-HT(3) receptor-mediated excitation in different subdivisions of the rat amygdala. Synapse 38, 328-337, http://dx.doi.org/10. 1002/1098-2396(20001201)38:3<328:AID-SYN12>3.0.CO;2-T.

Stein, J., Wiedholz, L., Bassett, D., Weinberger, D., Zink, C., Mattay, V., Meyer-Lindenberg, A., 2007. A validated network of effective amygdala connectivity. Neuroimage 36, 736-745, http://dx.doi.org/10.1016/j. neuroimage.2007.03.022

Surguladze, S.A., Elkin, A., Ecker, C., Kalidindi, S., Corsico, A., Giampietro, V., Lawrence, N., Deeley, Q., Murphy, D.G.M., Kucharska-Pietura, K., Russell, T.A., McGuffin, P., Murray, R., Phillips, M.L., 2008. Genetic variation in the serotonin transporter modulates neural system-wide response to fearful faces. Genes Brain Behav. 7, 543551, http://dx.doi.org/10.1111/j.1601-183X.2008.00390.x.

Surguladze, S.A., Radua, J., El-Hage, W., Gohier, B., Sato, J.R., Kronhaus, D.M., Proitsi, P., Powell, J., Phillips, M.L., 2012. Interaction of catechol O-methyltransferase and serotonin transporter genes modulates effective connectivity in a facial emotion-processing circuitry. Transl. Psychiatry 2, e70, http://dx.doi.org/10. 1038/tp.2011.69

Tan, H.-Y., Callicott, J.H., Weinberger, D.R., 2009. Prefrontal cognitive systems in schizophrenia: towards human genetic brain mechanisms. Cogn. Neuropsychiatry 14, 277-298, http://dx.doi.org/10.1080/13546800903091665.

Taylor, S.E., Way, B.M., Welch, W.T., Hilmert, C.J., Lehman, B.J., Eisenberger, N.I., 2006. Early family environment, current adversity, the serotonin transporter promoter polymorphism, and depressive symptomatology. Biol. Psychiatry 60, 671-676, http://dx.doi.org/10.1016/j.biopsych.2006.04.019.

Terburg, D., Syal, S., Rosenberger, L.A., Heany, S., Phillips, N., Gericke, N., Stein, D.J. van Honk, J., 2013. Acute effects of Sceletium tortuosum (Zembrin), a dual 5-HT reuptake and PDE4 inhibitor, in the human amygdala and its connection to the hypothalamus. Neuropsychopharmacology 38, 2708-2716, http://dx. doi.org/10.1038/npp.2013.183.

Thoma, P., Friedmann, C., Suchan, B., 2013. Empathy and social problem solving in alcohol dependence, mood disorders and selected personality disorders. Neurosci. Biobehav. Rev. 37, 448-470, http://dx.doi.org/10.1016/j.neubiorev. 2013.01.024.

Thomason, M.E., Henry, M.L., Paul Hamilton, J., Joormann, J., Pine, D.S., Ernst, M., Goldman, D., Mogg, K., Bradley, B.P., Britton, J.C., Lindstrom, K.M., Monk, C.S., Sankin, L.S., Louro, H.M.C., Gotlib, I.H., 2010. Neural and behavioral responses to threatening emotion faces in children as a function of the short allele of the serotonin transporter gene. Biol. Psychol. 85, 38-44, http://dx.doi.org/10.1016/ j.biopsycho.2010.04.009.

Tost, H., Kolachana, B., Hakimi, S., Lemaitre, H., Verchinski, B.A., Mattay, V.S., Weinberger, D.R., Meyer-Lindenberg, A., 2010. A common allele in the oxytocin receptor gene (OXTR) impacts prosocial temperament and human hypothalamic-limbic structure and function. Proc. Natl. Acad. Sci. U. S. A. 107 13936-13941, http://dx.doi.org/10.1073/pnas.1003296107.

Uher, R., McGuffin, P., 2010. The moderation by the serotonin transporter gene of environmental adversity in the etiology of depression: 2009 update. Mol. Psychiatry 15, 18-22, http://dx.doi.org/10.1038/mp.2009.123.

Van Donkelaar, E.L., Blokland, A., Ferrington, L., Kelly, P.a.T., Steinbusch, H.W.M., Prickaerts, J., 2011. Mechanism of acute tryptophan depletion: is it only serotonin? Mol. Psychiatry 16, 695-713, http://dx.doi.org/10.1038/mp.2011.9

Van Marle, H.J.F., Tendolkar, I., Urner, M., Verkes, R.J., Fernández, G., van Wingen, G., 2011. Subchronic duloxetine administration alters the extended amygdala circuitry in healthy individuals. NeuroImage 55, 825-831, http://dx.doi.org/10. 1016/j.neuroimage.2010.12.051.

Van der Does, A.J., 2001. The effects of tryptophan depletion on mood and psychiatric symptoms. J. Affect. Disord. 64, 107-119.

Van der Veen, F.M., Evers, E.A.T., Deutz, N.E.P., Schmitt, J.A.J., 2007. Effects of acute tryptophan depletion on mood and facial emotion perception related brain activation and performance in healthy women with and without a family history of depression. Neuropsychopharmacology 32, 216-224, http://dx.doi. org/10.1038/sj.npp.1301212.

Verge, D., Daval, G., Patey, A., Gozlan, H., el Mestikawy, S., Hamon, M., 1985. Presynaptic 5-HT autoreceptors on serotonergic cell bodies and/or dendrites but not terminals are of the 5-HT1A subtype. Eur. J. Pharmacol. 113, 463-464

Videtic, A., Peternelj, T.T., Zupanc, T., Balazic, J., Komel, R., 2009. Promoter and functional polymorphisms of HTR2C and suicide victims. Genes Brain Behav. 8 , 541-545, http://dx.doi.org/10.1111/j.1601-183X.2009.00505.x.
Vimaleswaran, K.S., Zhao, J.H., Wainwright, N.W., Surtees, P.G., Wareham, N.J., Loos, R.J.F., 2010. Association between serotonin 5-HT-2C receptor gene (HTR2C) polymorphisms and obesity- and mental health-related phenotypes in a large population-based cohort. Int. J. Obes. 34, 1028-1033, http://dx.doi. org/10.1038/ijo.2009.292.

Volman, I., Verhagen, L., den Ouden, H.E.M., Fernández, G., Rijpkema, M., Franke, B., Toni, I., Roelofs, K., 2013. Reduced serotonin transporter availability decreases prefrontal control of the amygdala. J. Neurosci. 33, 8974-8979, http://dx.doi. org/10.1523/JNEUROSCI.5518-12.2013.

Von dem Hagen, E.A.H., Passamonti, L., Nutland, S., Sambrook, J., Calder, A.J., 2011 The serotonin transporter gene polymorphism and the effect of baseline on amygdala response to emotional faces. Neuropsychologia 49, 674-680, http:/ dx.doi.org/10.1016/j.neuropsychologia.2010.12.013.

Walsh, N.D., Dalgleish, T., Dunn, V.J., Abbott, R., St Clair, M.C., Owens, M., Fairchild, G., Kerslake, W.S., Hiscox, L.V., Passamonti, L., Ewbank, M., Ban, M., Calder, A.J., Goodyer, I.M., 2012. 5-HTTLPR-environment interplay and its effects on neural reactivity in adolescents. NeuroImage 63, 1670-1680, http://dx.doi.org/10. 1016/j.neuroimage.2012.07.067.

Walters, J.T.R., Owen, M.J., 2007. Endophenotypes in psychiatric genetics. Mol. Psychiatry 12, 886-890, http://dx.doi.org/10.1038/sj.mp.4002068.

Wang, L., Ashley-Koch, A., Steffens, D.C., Krishnan, K.R.R., Taylor, W.D., 2012. Impact of BDNF Val66Met and 5-HTTLPR polymorphism variants on neural substrates related to sadness and executive function. Genes Brain Behav. 11, 352-359, http://dx.doi.org/10.1111/j.1601-183X.2012.00764.x.

Waring, J.D., Etkin, A., Hallmayer, J.F., O'Hara, R., 2014. Connectivity underlying emotion conflict regulation in older adults with 5-HTTLPR short allele: a preliminary investigation. Am. J. Geriatr. Psychiatry 22, 946-950, http://dx.doi. org/10.1016/j.jagp.2013.08.004.

Wendland, J.R., Martin, B.J., Kruse, M.R., Lesch, K.-P., Murphy, D.L., 2006. Simultaneous genotyping of four functional loci of human SLC6A4, with a reappraisal of 5-HTTLPR and rs25531. Mol. Psychiatry 11, 224-226, http://dx. doi.org/10.1038/sj.mp.4001789.

Wiggins, J.L., Bedoyan, J.K., Carrasco, M., Swartz, J.R., Martin, D.M., Monk, C.S., 2014. Age-related effect of serotonin transporter genotype on amygdala and prefrontal cortex function in adolescence. Hum. Brain Mapp. 35, 646-658, http://dx.doi.org/10.1002/hbm.22208.

Williams, W.A., Shoaf, S.E., Hommer, D., Rawlings, R., Linnoila, M., 1999. Effects of acute tryptophan depletion on plasma and cerebrospinal fluid tryptophan and 5-hydroxyindoleacetic acid in normal volunteers. J. Neurochem. 72, 1641-1647.

Williams, J.H.G., Perrett, D.I., Waiter, G.D., Pechey, S., 2007. Differential effects of tryptophan depletion on emotion processing according to face direction. Soc. Cogn. Affect. Neurosci. 2, 264-273, http://dx.doi.org/10.1093/scan/nsm021.

Willins, D.L., Deutch, A.Y., Roth, B.L., 1997. Serotonin 5-HT2A receptors are expressed on pyramidal cells and interneurons in the rat cortex. Synapse 27, 79-82, http://dx.doi.org/10.1002/(SICI)1098-2396(199709)27:1<79:AIDSYN8>3.0.CO;2-A.

Windischberger, C., Lanzenberger, R., Holik, A., Spindelegger, C., Stein, P., Moser, U., Gerstl, F., Fink, M., Moser, E., Kasper, S., 2010. Area-specific modulation of neural activation comparing escitalopram and citalopram revealed by pharmaco-fMRI: a randomized cross-over study. NeuroImage 49, 1161-1170, http://dx.doi.org/10.1016/j.neuroimage.2009.10.013.

Wise, R.G., Tracey, I., 2006. The role of fMRI in drug discovery. J. Magn. Reson. Imaging 23, 862-876, http://dx.doi.org/10.1002/jmri.20584.

World Health Organization, 1992. The ICD-10 Classification of Mental and Behavioural Disorders: Clinical Descriptions and Diagnostic Guidelines, 10th ed. World Health Organization, Geneva.

Wurtman, R.J., Hefti, F., Melamed, E., 1980. Precursor control of neurotransmitter synthesis. Pharmacol. Rev. 32, 315-335.

Young, S.N., 2013. Acute tryptophan depletion in humans: a review of theoretical, practical and ethical aspects. J. Psychiatry Neurosci. 38, 294-305, http://dx.doi. org/10.1503/jpn.120209.

Yuen, E.Y., Jiang, Q., Chen, P., Feng, J., Yan, Z., 2008. Activation of 5-HT2A/C receptors counteracts 5-HT1A regulation of $n$-methyl-D-aspartate receptor channels in pyramidal neurons of prefrontal cortex. J. Biol. Chem. 283, 17194-17204, http://dx.doi.org/10.1074/jbc.M801713200.

Zammit, S., Owen, M.J., 2006. Stressful life events, 5-HTT genotype and risk of depression. Br. J. Psychiatry 188, 199-201, http://dx.doi.org/10.1192/bjp.bp. 105.020644.

Zhou, F.-M., Liang, Y., Salas, R., Zhang, L., De Biasi, M., Dani, J.A., 2005. Corelease of dopamine and serotonin from striatal dopamine terminals. Neuron 46, 65-74, http://dx.doi.org/10.1016/j.neuron.2005.02.010.

Zhou, Z., Zhen, J., Karpowich, N.K., Law, C.J., Reith, M.E.A., Wang, D.-N., 2009. Antidepressant specificity of serotonin transporter suggested by three LeuT-SSRI structures. Nat. Struct. Mol. Biol. 16, 652-657, http://dx.doi.org/10. 1038/nsmb.1602.

\section{Web References}

http://www.nimh.nih.gov/research-priorities/rdoc/index. shtml (accessed 09.07.16.)

http://www.nimh.nih.gov/research-priorities/rdoc/rdocconstructs.shtml (accessed 09.07.16.). 